\title{
الرقابة القضائية على السلطة التقديرية للإدارة
}

\author{
وليد عبدالرحمن مزهر
}

أستاذ القانون العام المساعد- جامعة الأقصى- غزة، فلسطين

wa.mezher@alaqsa.edu.ps

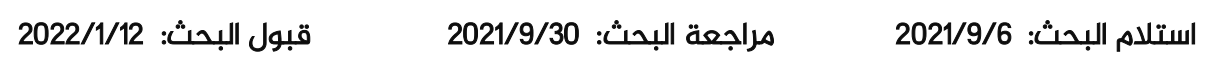

DOI: https://doi.org/10.31559/LCJS2021.2.3.4

@e) This file is licensed under a Creative Commons Attribution 4.0 International 
www.refaad.com
المجلة الدولية للدراسـات القانونية والفقهية المقارنة

International Journal of Legal and Comparative Jurisprudence Studies (LCJS)

Journal Homepage: https://www.refaad.com/views/LCJS/Home.aspx

ISSN: 2708-6607(Online) 2708-6593(Print)

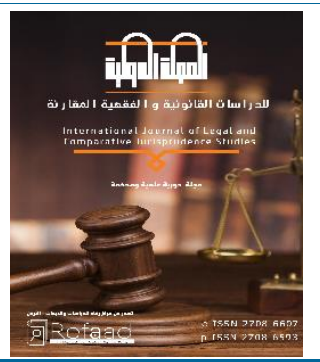

الرقابة القضيائية على السلطة التقديرية للإدارة

\author{
وليد عبدالرحمن مزهر \\ أستاذ القانون العام المساعد- جامعة الأقصى- غزة، فلسطين \\ wa.mezher@alaqsa.edu.ps
}

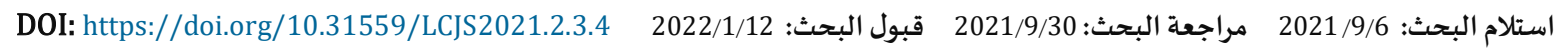

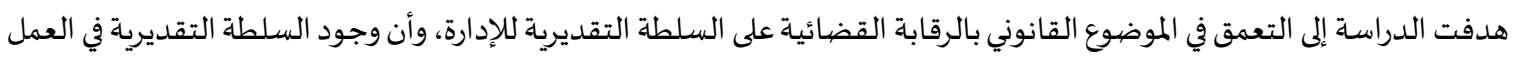
الاداري من شأنه أن يحقق وجود الدولة القانونية هذا من جهة ومن جهاة أخرى من شأنه تسيير وحسن أداء المرافق العامة الإدارية، ولأهميتها تم استخدام المنهج الوصفي التحليلي وكذلك المقارن، ولهذا تم تقسيم الدراسة إلى ثلاثة مباحث حيث تناولنا في المبحث الأول على ماهية

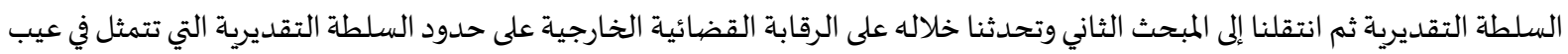

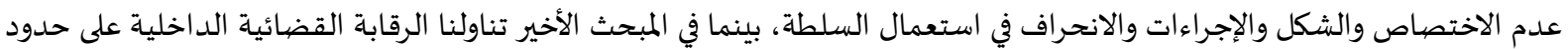
السلطة التقديرية وتحدثنا خلاله على عيب السبب وعيب المحل، وقد توصلنا إلى عدة نتائج وتوصيات وكان من أهم النتائج السلطة التقديرية للإدارة تكمن في عنصر السبب والمحل والغاية أما السلطة المقيدة فتكون في الاختصاص والشكل. بينما أهم التوصيات تتمثل في الأمل من

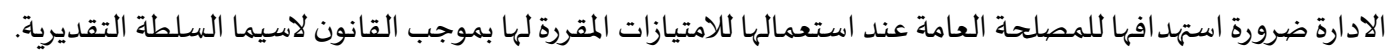
الكلمات المفتاحية: الرقابة القضائية؛ السلطة التقديرية؛ القضاء الإداري؛ عيب عدم الاختصاص؛ عيب الشكل؛ عيب السبب؛ عيب المحل.

أضحت الإدارة في الوقت المعاصر تمارس العديد من الاختصاصات لا سيما بعد تحول مفهوم الدولة من المفهوم التقليدي" الدولة الحارسـ" إلى المفهوم الحديث " الدولة المتدخلة"، حيث أن دورها لم يعد مقتصراً على حفظ النظام العام بعناصر الثلاثة بل امتد ليشمل كافة الأنشطة الحياتي

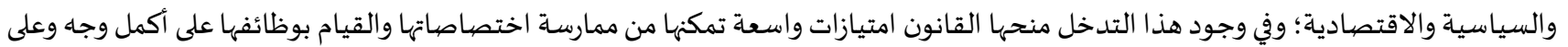

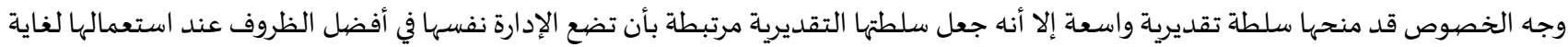

تحقيق الغرض المنشود وهو تحقيق المصلحة العامة.

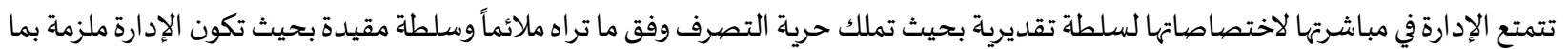
حدده القانون، فالسلطة التقديرية والمقيدة تستمد أحكامها من نصوص القانون والمبادئ العامة له.

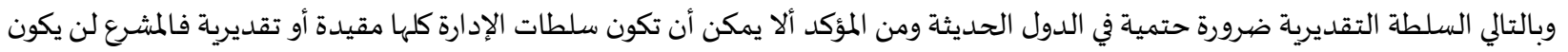

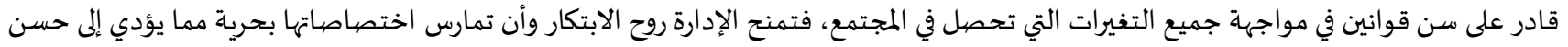

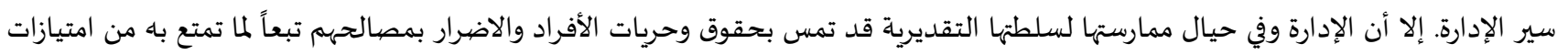

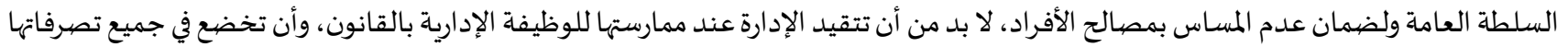

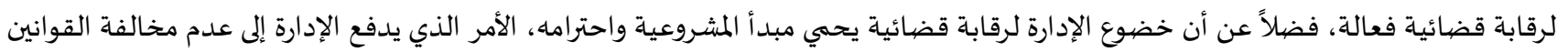
والأنظمة فيما تقوم باه من عمل إداري كذلك تتجنب الأخطاء التي توجب المسئولية الإدارية. 
أهمية الدراسـة:

تتجلى أهمية الدراسة في كون السلطة التقديرية للإدارة باتت ضرورة ملحة في الوقت الحالي نتيجة تطور واتساع النشاط الإداري الذي فرض على النه المشرع منح الإدارة بعض الامتيازات التي تقوم على الابتكار والتجدد مسايرة مع التطورات الحاصلة في عالم الإدارة لاسيما وأن القانون الإداري قانون مرن

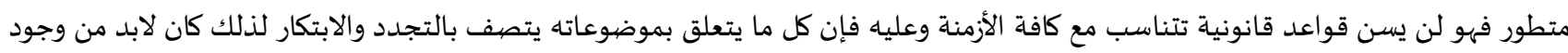

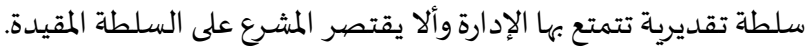

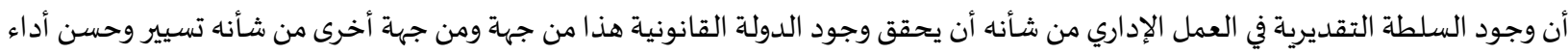

المرافق العامة الإدارية.

أهداف الدراسة:

التعرف على طبيعة السلطة التقديرية للإدارة والتفرقة بينها وبين السلطة المقيدة. بيان دور القضاء في المراقبة على أعمال الإدارة وتحقيقه لحماية مبدأ المشروعية وحماية الحقوق والحريات الفردية. التعرف على حدود السلطة التقديرية من خلال أركان القرار الإداري ومدى الرقابة عليها. التعرف على مبررات وجود هذه النظرية وماهية ضوابطها.

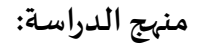

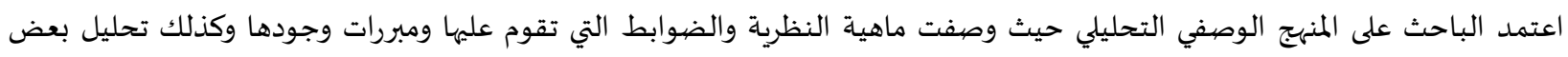

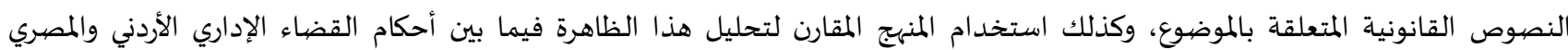
والفلسطيني.

مشكلة الدراسـة: تكمن مشكلة الدراسة في تجاوز الإدارة للسلطات المخولة لها بموجب القانون وتعمدها في بعض الأحيان إلى الإضرار بمصالح الأفراد في حالة عدم

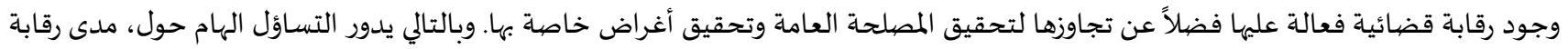

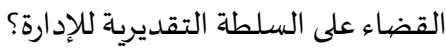

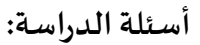

ما هو مفهوم السلطة التقديرية وما هي مبررات وجودها؟ ما هي حدود الرقابة القضائية الخارجية للسلطة التقديرية للإدارة؟ ما هي الرقابة القضائية على الحدود الداخلية على السلطة التقديرية للإدارة؟

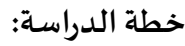

المبحث الأول: ماهية السلطة التقديرية.

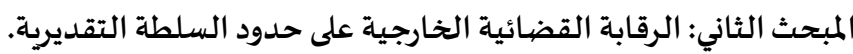

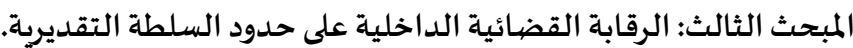

\section{المبحث الأول: ماهية السلطة التقديرية}

تقوم كل جهة إدارية بمباشرة نشاطها وفقاً للقانون ويكون لها في حدوده سلطة تقديرية، وذلك سواء كان من جهاة تدخلها أو امتناعها، فالسلطة

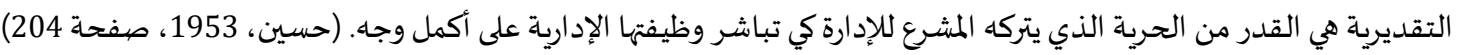

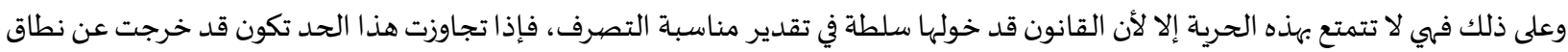

القانون، وبالتالي عن نطاق المشروعياة، والسلطة التقديرية لازمة لحسن سير الإدارة، إذ أن المشروعية تثقل كاهل الإدارة، ولا يجب الإفراط فيها.

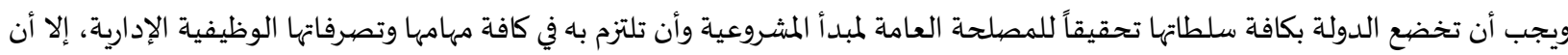

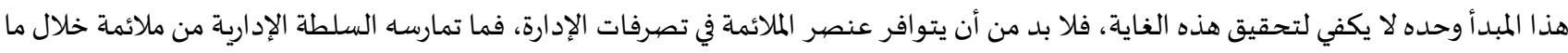

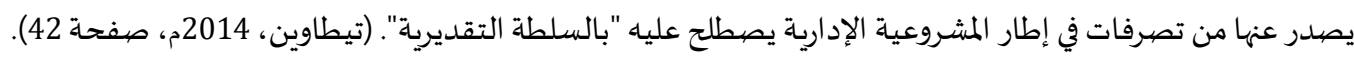

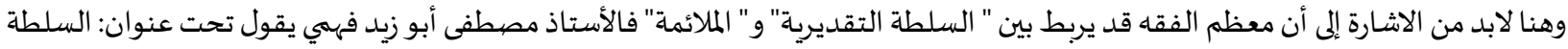

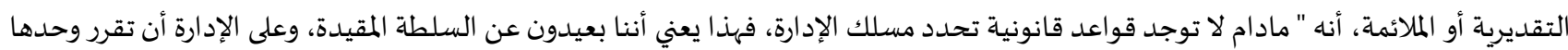
أن هذا الاجراء ملائم أو غير ملائم، فهي وحدها القادرة على ملائمة قراراتها للظروف الواقدية 
المطلب الأول: مفهوم السلطة التقديرية

أولاً: التعريف اللغوي للسلطة التقديرية:

هي إمكانية التصرف الحر، أي التصرف طبقاً لإرادة صاحب التصرف وطبقاً لمحض رغبته الذاتية، ويقصد بكلمة تقدير من الناحية اللغوية امكانية

التقدير الحر، أي التصرف طبقاً لإرادة صاحب التصرف، وطبقاً لمحض رغبته الذاتية. (تيطاوين، 2014م، صفحة

ثانياً: التعريف الاصطلاحي للسلطة التقديرية:

إن المشرع كثيراً ما يترك للإدارة قدراً من الحرية في التصرف وفقاً للظروف دون معقب عليها ولقد عرّف العميد بونار السلطة التقديرية للإدارة:"

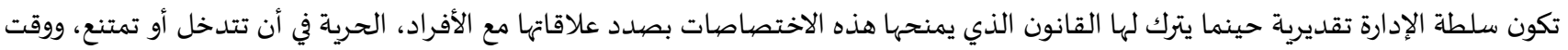

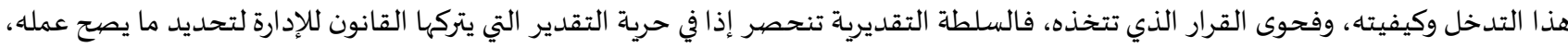

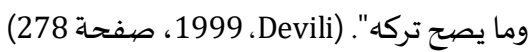

أما موريس هوريو فيعرف السلطة التقديرية بأها:" سلطة تقدير مدى ملاءمة الإجراءات الإدارية". (نجم، 1982، صفية صفحة 46) أما الفقيه الفرنسي ميشو فيري:" أن السلطة التقديرية تتحقق في كل مرة تستطيع فيها السلطة الإدارية أن تعمل بحرية، ودون أنسان أن يكون هناك

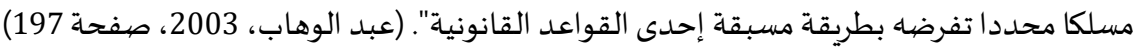

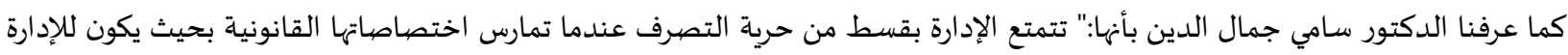

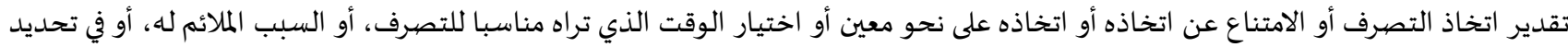
محله". (جمال الدين، صفحة 145) وإن مجال أعمال السلطتين التقديرية والمقيدة، هو موضيوع القرار الإداري، وعلى وجه التحديد هو الاتصال بين الأسباب والظروف الواقعية،

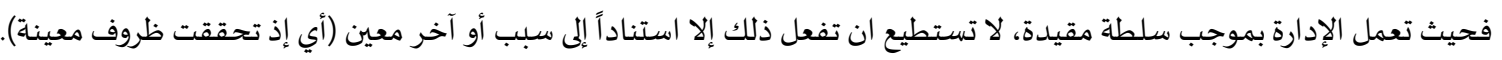

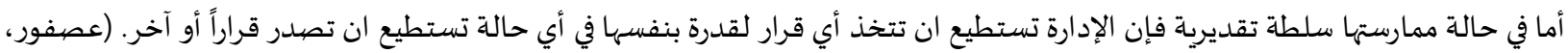

110 1957م، صفحة

ويقول الدكتور محمد فؤاد مهنا" ما دام انه لا توجد قواعد أند قاندونية تحدد مسلك الإدارة فمعنى هنا أننا بعيدون عن السلطة المقيدة، وعلى الإدارة

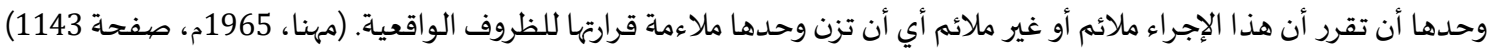

ثالثثاً: التعريف القضائي للسلطة التقديرية: عرفت محكمة القضاء الإداري المصرية بقولها:" إن قضاء هذه المحكمة قد استقر على أن الجهة الإدارية تستقل بتقدير مناسبة إصدار قراراتها

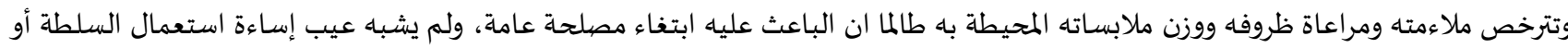

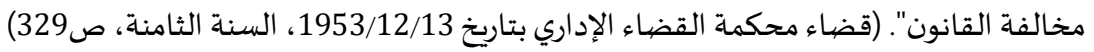

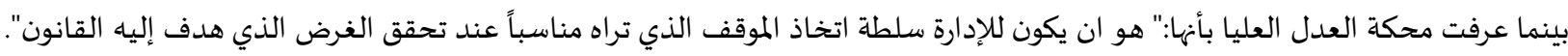

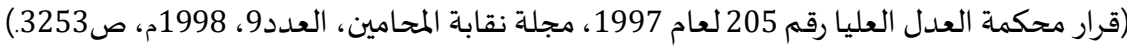

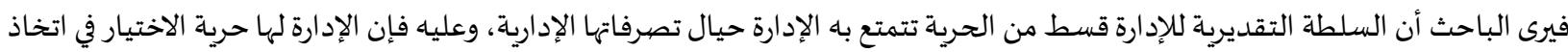

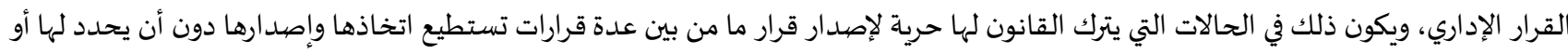

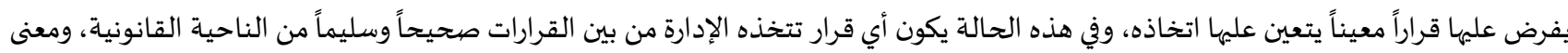

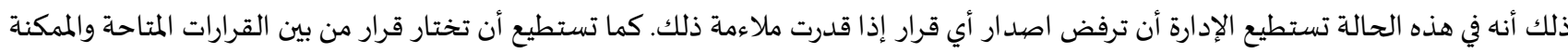

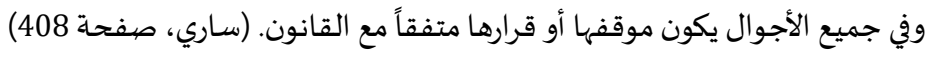

المطلب الثاني: مبررات السلطة التقديرية

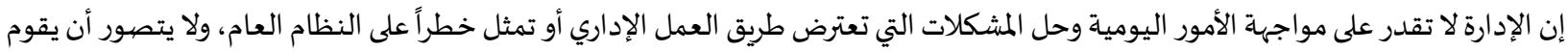

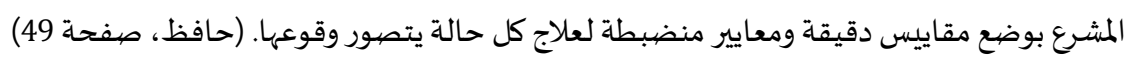

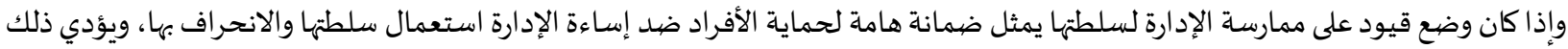

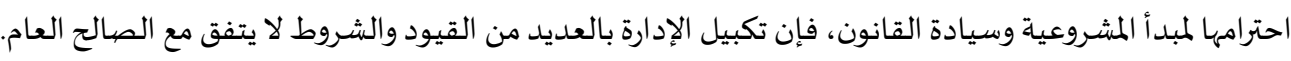

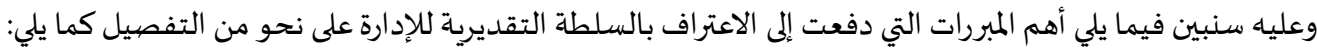

أولاً: استحالة وضع قواعد عامة لكافة تفاصيل الحياة الإدارية: لقد لاحظ الفقهاء أنه يكاد أن يكون مستحيلاً أن يضع المشرع قاعدة لهدة عامة مجردة تعالج كافة تفاصيل الحياة الإدارية بما فيها من تعقيدات المراكز

الفردية. (حافظ، صفحة 49) 
لذلك كان من المحتم أن يقتصر التشريع على وضع القواعد والمبادئ العامة وأن يترك للدارة سلطة معالجة الحالات الفردية بما يتفق مع ظروف

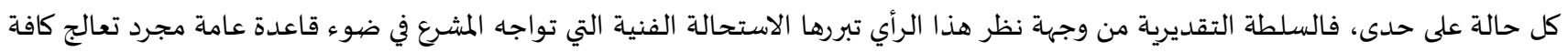
تفاصيل الحياة الإدارية وعدم امكان التنبؤ بكافة احتمالات المراكز الفردية، والواقع أن هذا التفسير التقليدي صحيح إلى حد ما، ذلك تن مما لاشك فيك فيه

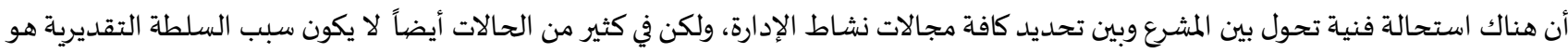

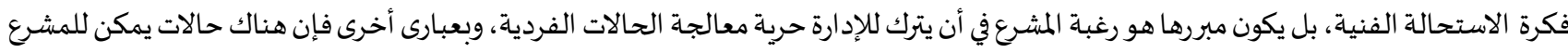

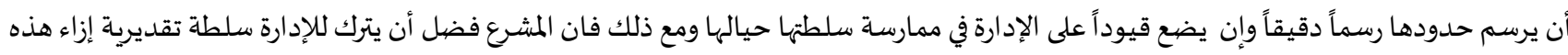

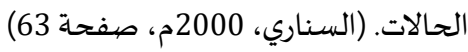

ثانياً: فكرة الصلاحية الإدارية:

ويرى بعض الفقه أن مبرر السلطة التقديرية هو قدرة الإدارة على مواجهة وتقدير وملائمة تصرفاتها وفقاً للظروف والملابسات وذلك بما لهابها لها من خبرة وما يوجد تحت تصرفها من وسائل فنية ومعلومات، وذلك على عكس القاضي الذي لا يعيش في أحداث النزاع، فهو عادة بعيد عن المكان الذي تتم فئه

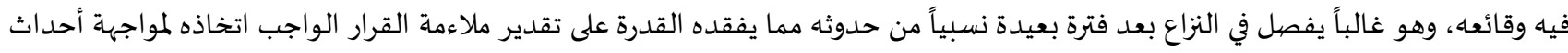

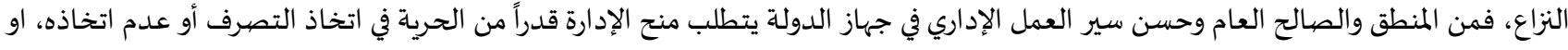

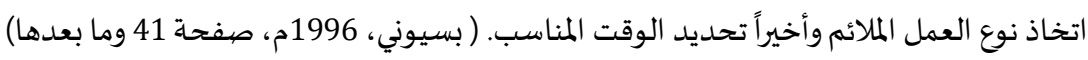
فقضت محكمة العدل العليا في مجال الصلاحية التقديرية في مجال تمديد الآجال المنصوص عليها في القانون" صلاحية مسجل العلامات التجارية، صلاحية تقديرية يمارسها وفق مقتضيات وظروف العمل وليس في ظروف الدعوى ما يشير إلى ان مسجل العلامات التجارية قد خالف أحكام المادة (40)

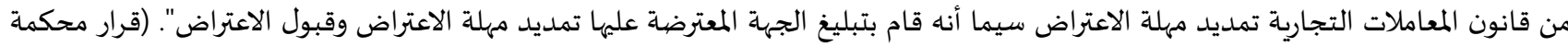

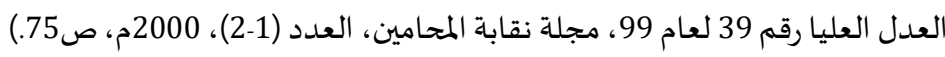
ثالثاً: السلطة التقديرية ضرورية لفاعلية العمل الإداري: أن السلطة التقديرية شرط ضروري لكفالة فاعلية العمل الإداري، ذلك لأن الاختصاص المقيد التهايد غالباً ما يفقد العمل الإداري فاعليته فالإدارة مكلفة

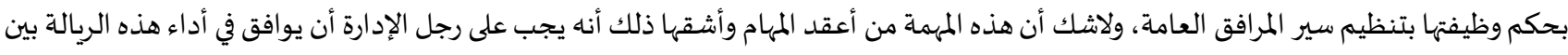

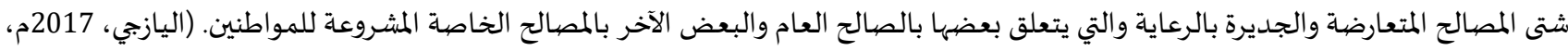

صفحة 81)

فإذا كان رجل الإدارة ليس إلا منفذاً حرفياً للقوانين واللوائح لأدى ذلك إلى شلل الإدارة، وإلى فقدان فاعلية العمل الإداري ذلك أن فاعلية العمل

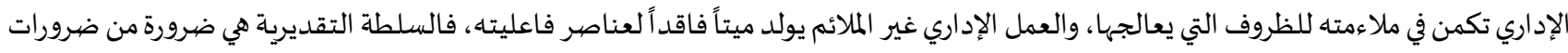
الفاعلية الإدارية، فإن منح الإدارة سلطة تقديرية يتحقق للتوفيق والملاءمة بين اعتبارين أساسين هما الكفاءة الإدارية وحماية حقوق وحريات الأفراد

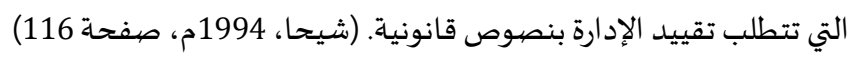
رابعاً: تفادي عيوب السلطة المقيدة:

إن تفادي عيوب السلطة المقيدة يمكن أن يكون مبرراً للاعتراف بنصيب من السلطة التقديرية للإدارة، فإذا كانت السلطة المقيدة تبدو لأول وهلة

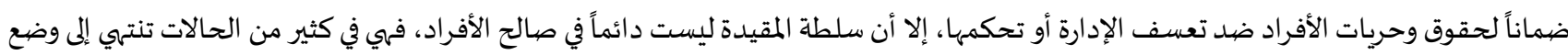

عراقيل في سبيل العمل الإداري وتؤدي من الناحية العملية إلى بطء وارتباك العمل الإداري.

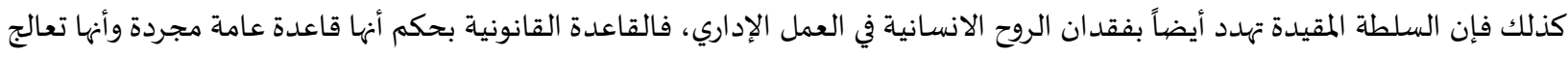

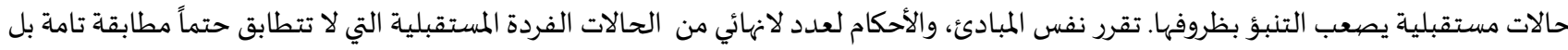

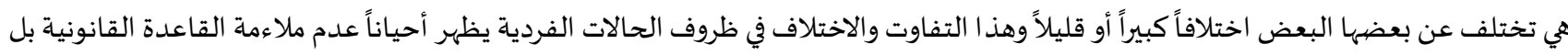
وقسوتها في التطبيق الفردي ومن أجل هذا فإن الإدارة يمكنها عن طريق السلطة التقديرية أن تبعث في التطبيق الفردي للقاعدة القانونية تلك الروح

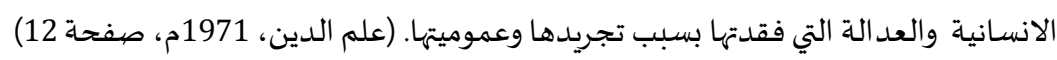

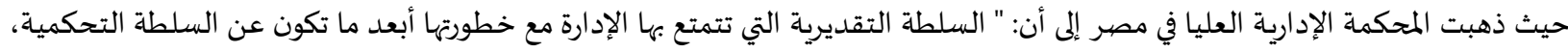

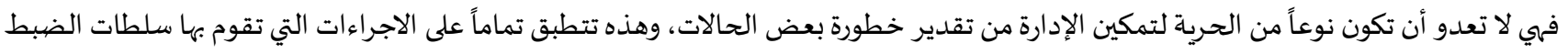

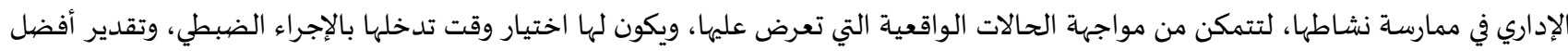

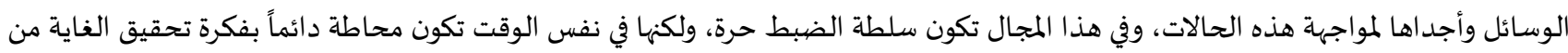

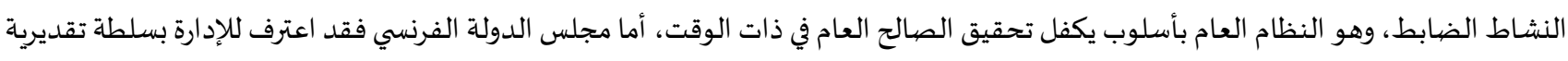
لتيسير العمل الإداري، حيث منح الإدارة سلطة تقدير إنشاء أو عدم إنشاء المرافق العامة، طالما لم يلزهها القانون بذلك، ولكنها قيد سلطة الإدارة في 
إلغاء المرافق التي وافقت على إنشـاءها وارتبطت بها مصالح الجماهير بضرورة أن يكون ذلك لضرورات المصلحة العامة. ( خليفة، الانحراف بالسلطة

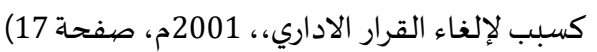

\section{المبحث الثاني: الرقابة القضائية الخارجية على حدود السلطة التقديرية}

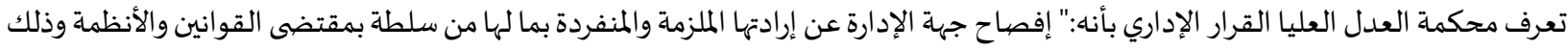

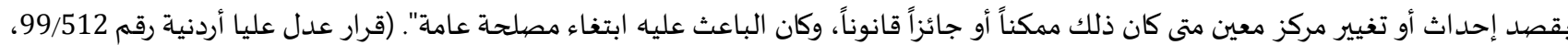

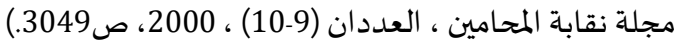
وعلى ذلك يمكننا تحديد أركان القرار الإداري بأنه يتكون من خمسة أركان أو عناصر وهي ركن السبب، وركن الشكل، وركن الاختصاص، وركن المحل، وركن الغاية.

ويقصد بالعناصر الخارجية للقرار الإداري، عنصر الاختصاص، وعنصر الشكل، وإن توزيع الاختصاصات بين الجهات الإدارية والهيئات يراعى فيها

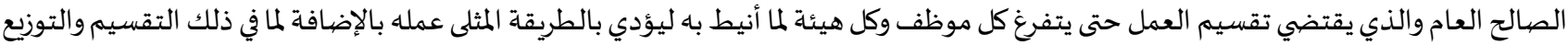
من مصلحة للأفراد حتى يسهل توجيههم إلى أقسام الإدارة المختلفة.

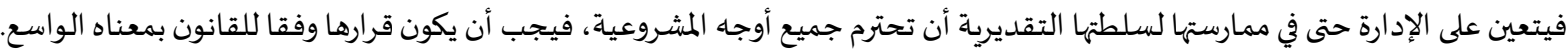

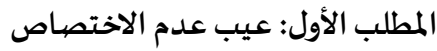
يقوم القانون العام الحديث، على فكرة الاختصاص، وتحديد اختصاصات معينة لرجل الإدارة، هو نتيجة من نتائج مبدأ الفصل بين السلطات،

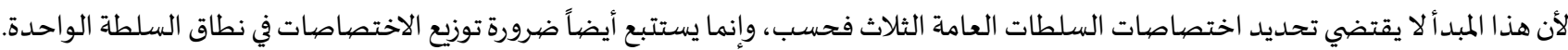

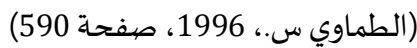

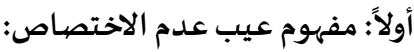

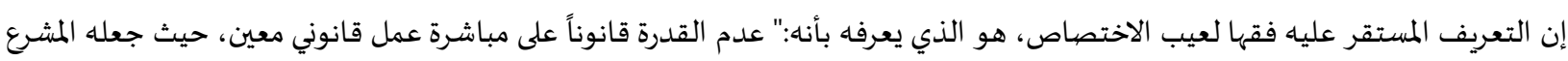

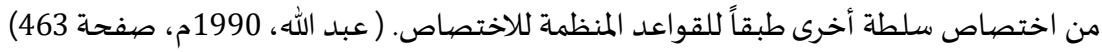

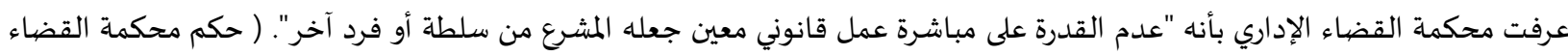

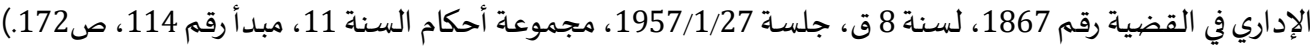

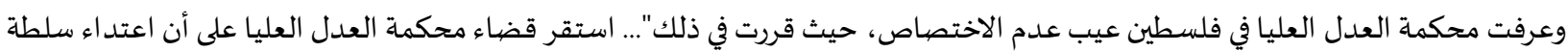

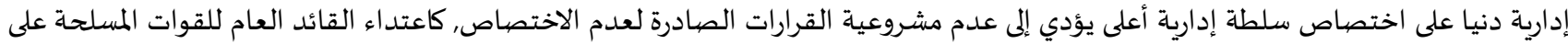

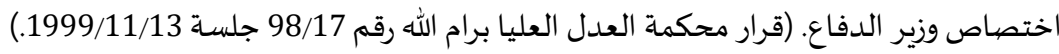

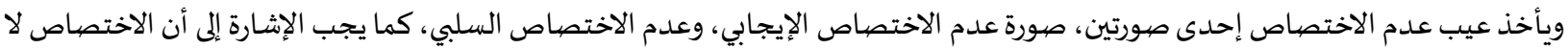

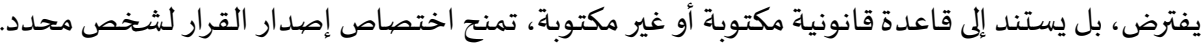

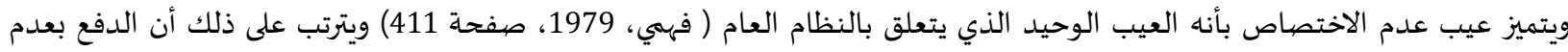

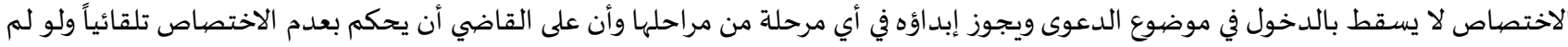
بثيره طالب الإلغاء. فعيب عدم الاختصاص هو أول وأقدم سبب من أسباب الحكم بالإلغاء وهو العيب الذي يصيب القرار الإداري من حيث ركن الاختصاص، فهو الإداء

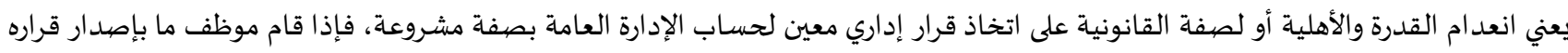

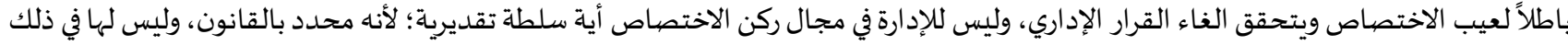

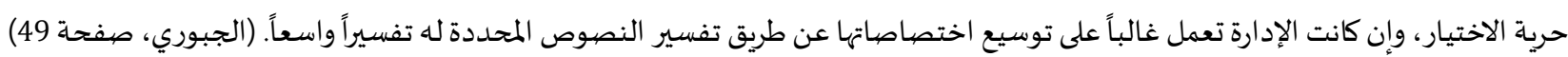

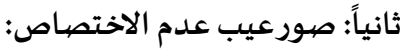
تنقسم صور عيب عدم الاختصاص إلى عيب عدم اختصاص جسيم يعرف باغتصاب السلطة وعيب عدم الاختصاص بسيط.

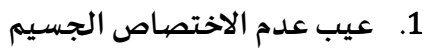
يطلق الفقه والقضاء على عيب عدم الاختصاص الجسيم اصطلاح " اغتصاب السلطة " ويكون من أثره فقدان القرار لصفتهاه وطبيعته الإدارية فلا

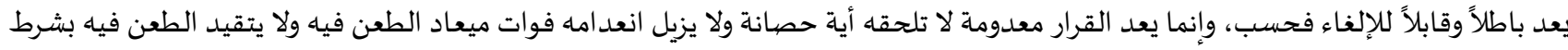

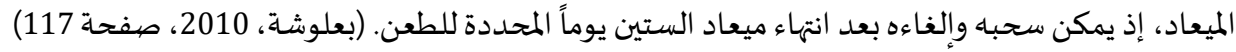


قد تبلغ مخافة القرار الإداري لركن الاختصاص، حداً من الجسامة لدرجة تفقده صفته الإدارية، حيث يتحول إلى عمل مادي، حيث يكون مصدره

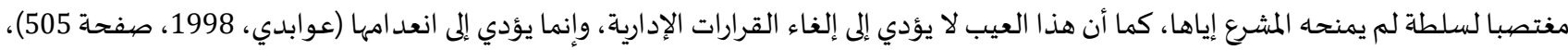
ويظهر عدم الاختصاص الجسيم في عدة حالات هي: أ. و. صدور القرار الإداري من فرد عادي:

يقصد باه صدور القرار من شخص لا يتمتع بأي صفة إدارية تخوله إصدار القرار الإداري إما لعدم تقلده الوظيفة أصلاً أو أن القرار قد صددر في وقت كانت صفته كموظف عام زالت عنه السبب من الأسباب، فيعتبر القرار الصادر منه عندئذ منعدمة ولا يرتب أي آثار قانونية لافتقاده شرطة

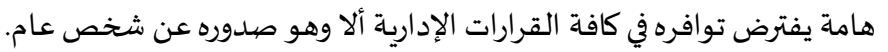

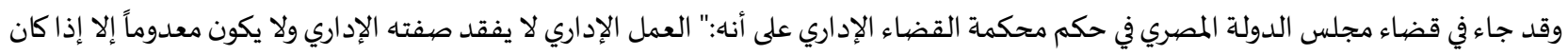

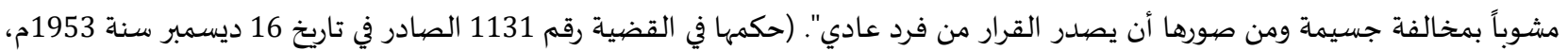

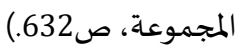
وأكدت محكمة العدل العليا على هذه الحالة في حكم صدر لها حيث عددت أن القرار منعدماً إذا صدر من فرد عادي، أو هيئة غير مختصية حيث

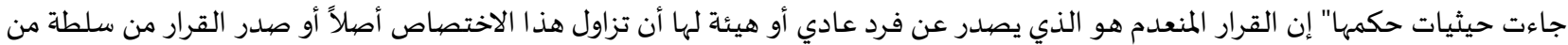

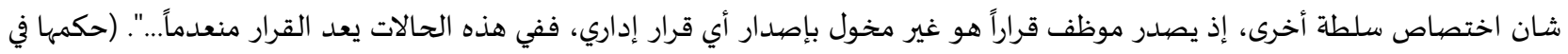

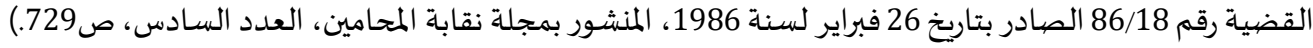

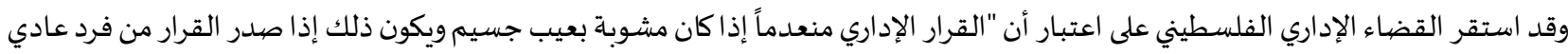
أو هيئة لا تختص أصلاً بمزاولة هذا الاختصاص، أو صدر القرار من سلطة في شأن من اختصاص سلطة أخرى كان تتولى السلطة الإدارية عملاً من

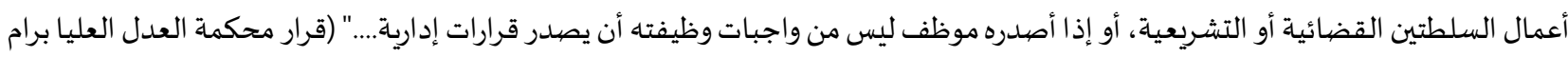
الله في الطلب رقم ب. اعتداء السلطة التنفيذية على اختصاصات السلطة التشريعية والتنفيذية.

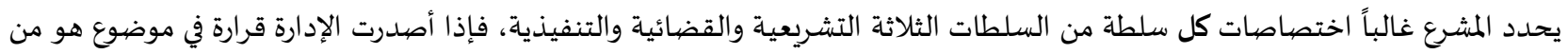
اختصاص السلطة التشريعية أو القضائية فإن قرارها هذا يكون من قبيل اغتصاب السلطة. (ليلو، 2008، صفحة 168)

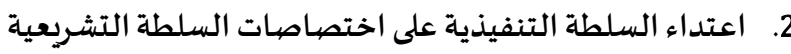
ويظهر عيب عدم الاختصاص الجسيم في هذه الصيورة بتناول القرار الإداري تنظيم أمر لا يمكن تنظيمها إلا بقانون وفقاً لأحكام الدستور (السناري، إدهاء 2000م، صفحة 205) إذا خرجت الإدارة عن النطاق المحدد لها في حقل التنظيم العام وتطاولت إلى ما هو من اختصاص السلطة التشريعية يكون عملها مشوبا باغتصاب السلطة ومستلزماً البطلان كأن تنشئ السلطة التنفيذية محكمة إدارية بقرار إداري.

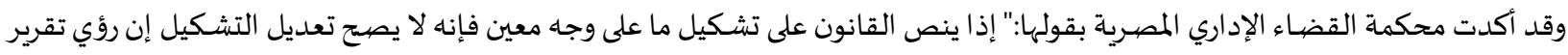

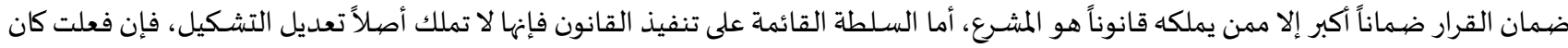

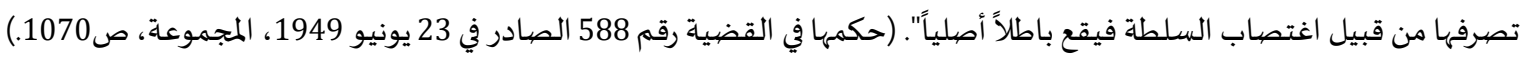

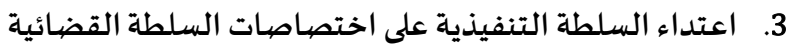

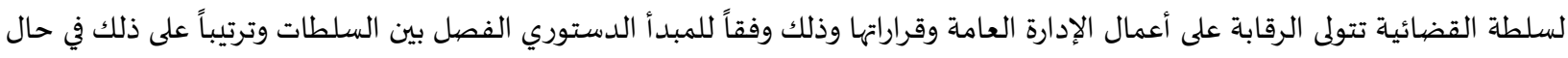

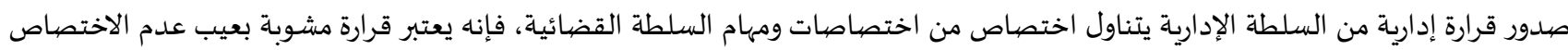

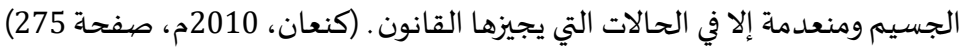

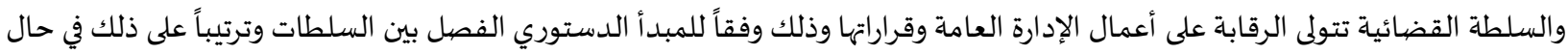

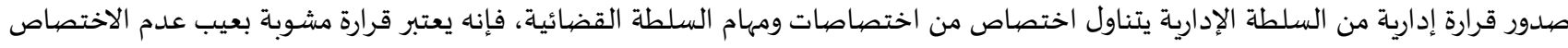

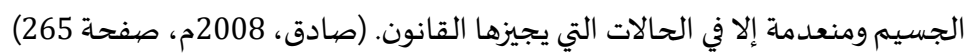
ولقد أقر القضاء الإداري الفلسطيني في العديد من أحكامه بعدم مشـروعية القرارات الإدارية الصادرة من الإدارة التي تعتدي بها على اختصاصاصات

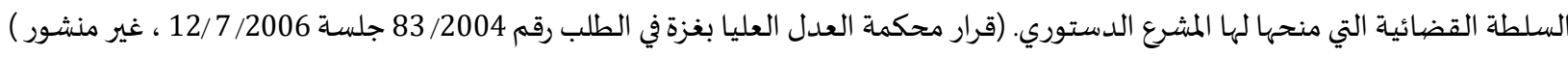
4.

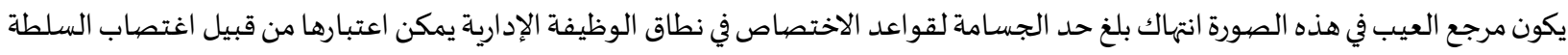

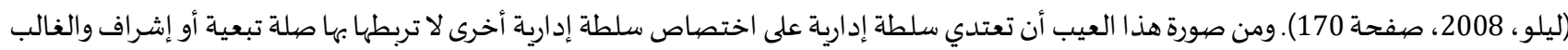
يكون المشـع قد جعل السلطتين على قدم المساواة وقد سمى الفقه القانوني الإداري هذه الصهورة الاعتداء الجانبي على السلطة. 
ومن المبادئ التي استقر عليها القضاء الإداري المصري في أحكامه في هذه الصورة بأن" صدور القرار الإداري من جهة غير منوط بها إصلداره قانونا

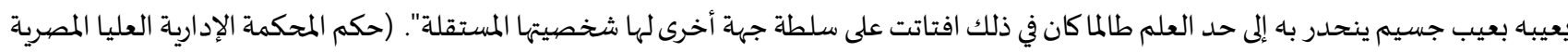

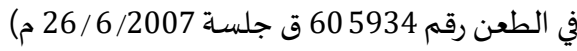

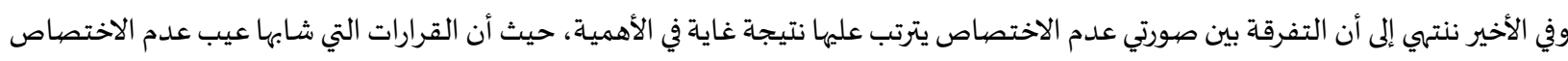

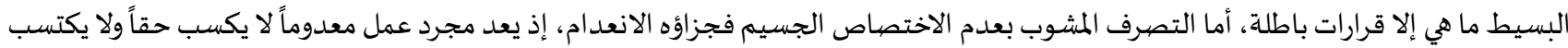
حصانة ولا يتقيد الطعن بإلغائه بميعاد.

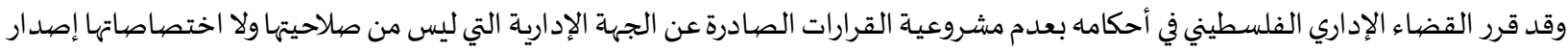

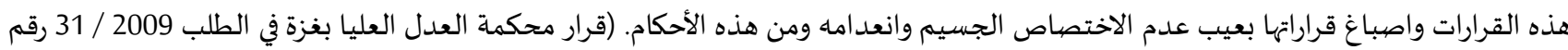

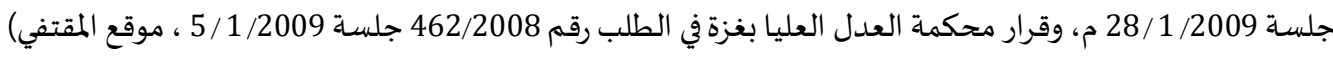

5. العيب عدم الاختصاص البسيط يكون حينما يقع في داخل النطاق الإداري، و هذه الصورة هي الأكثر شيوعا يظهر عيب عدم الإن الاختصاص البسيط في في نطاق السلطة الإدارية ذاتها أي

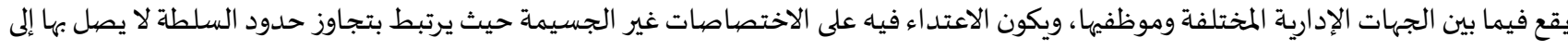

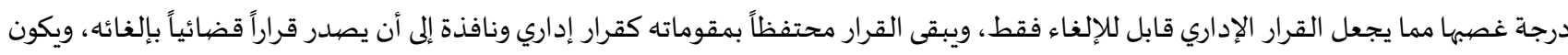

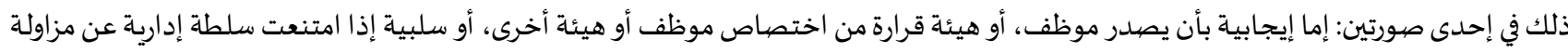

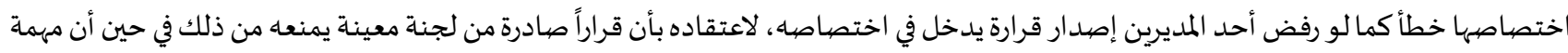

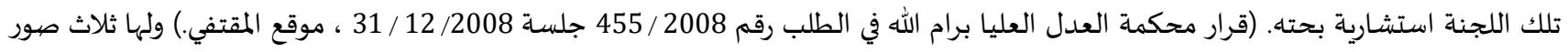
تقليدية

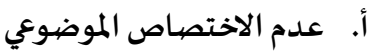

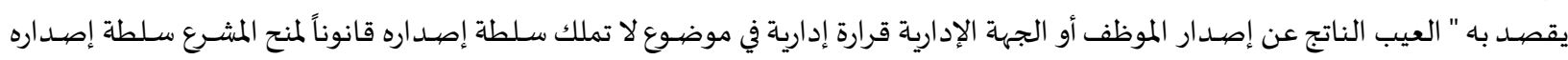

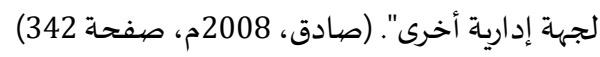

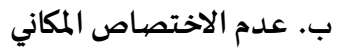

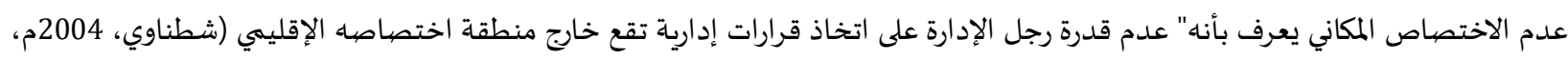

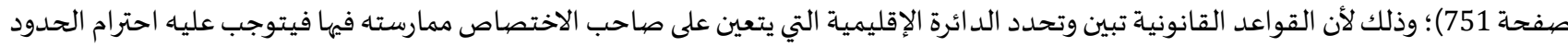

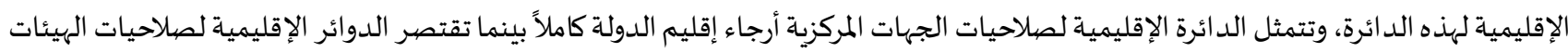

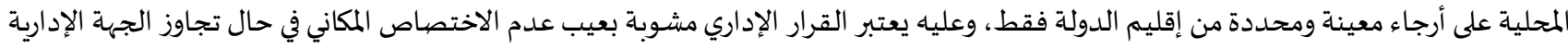
المصدرة القرار نطاق دائرة اختصاصهاء الإقليمي.

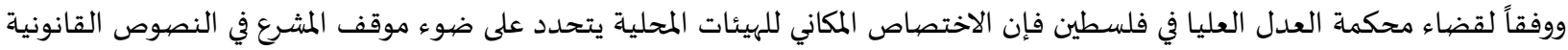

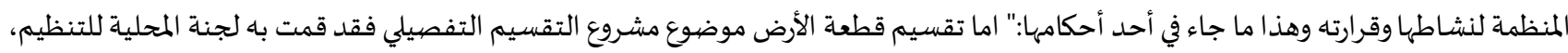

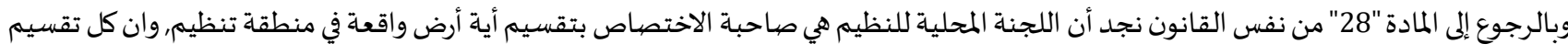

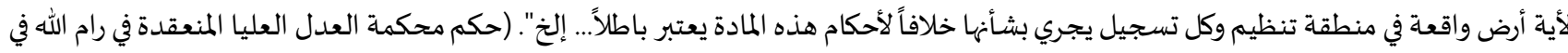

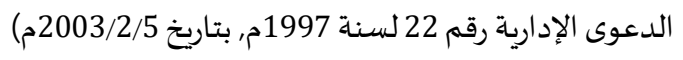
ج. عدم الاختصاص الزماني

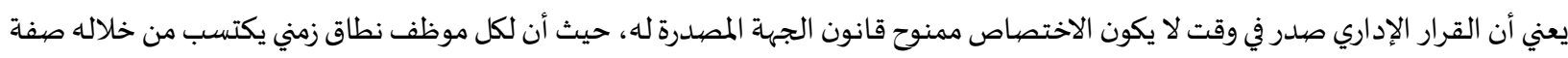

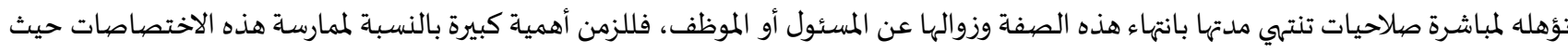

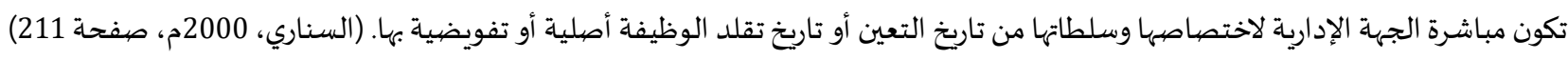
المطلب الثاني: عيب الشكل والإجراءات

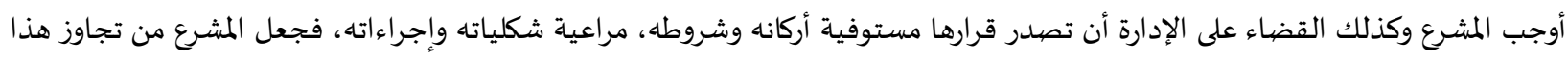

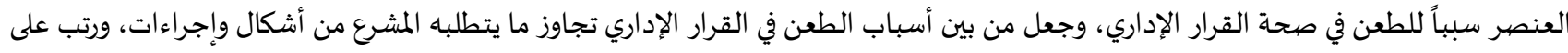

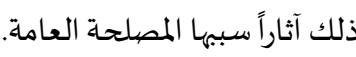
أولاً: التعريف بعيب الشكل وقد ثار التساؤل حول ما إذا كان الإجراء يُعدُّ عُنصراً من عناصر الشّّكل أم أنه مستقل عنه؟ ولإجابة عن هذا التساؤل، انقسم الفقه الإداري إلى 
فذهب جانب من الفقه إلى التفرقة بين الشّكل والإجراء في القرار الإداري وعدم اعتبارهما عنصراً واحداً يُشكل سبباً من أسباب الإلغاء، ويستند

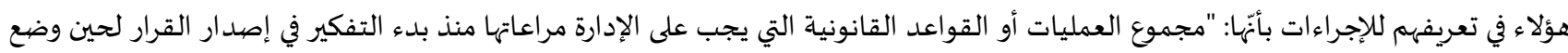
القرار في القالب أو الصورة التي يصدر فيها. وتعريفهم للشكل بأنه الإطار أو الصورة التي تظهر فيها إرادة الإدارة المنفردة بشكلها النهائي. ( حسن، التعويض

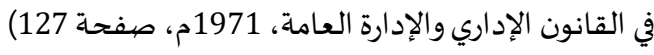
في حين ذهب جانب آخر من الفقه الإداري إلى اعتبار الإجراء من عناصر الشّكل على أساس أن المقصود بالشكل المظهر الخارجي الذي يتّخذه القرار

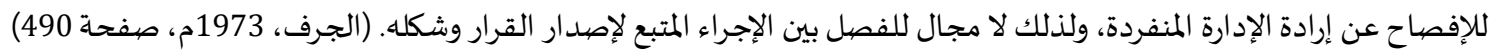

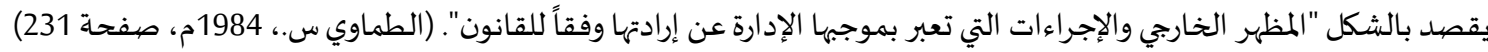

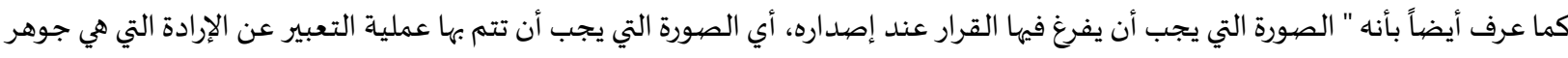

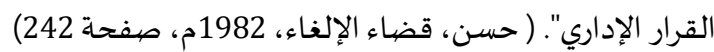

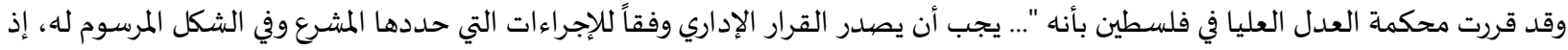

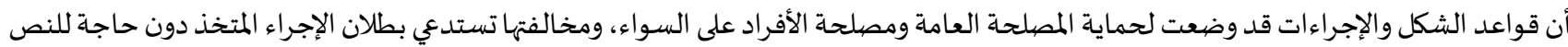

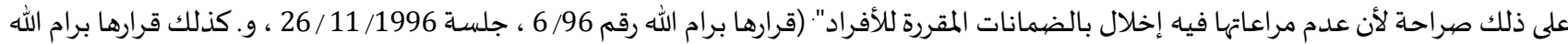

رقم 8/96 ، جلسة ثانياً: صور الشكل والإجراءات في القرار الإداري

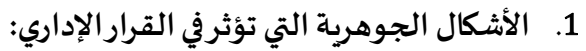

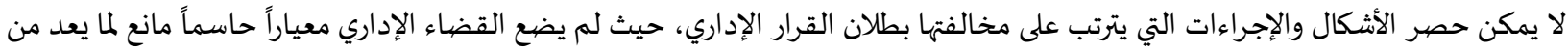

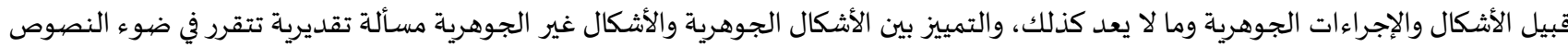
القانونية ورأي المحكمة.

\section{الإجراءات التمهيدية لإصيدار القرار الإداري}

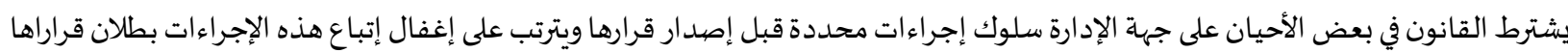
كما في الإجراءات الاستشارية مثل: قد يتطلب المشرع في بعض الأحيان على الجهاة الإدارية قبل إصدار قرار إداري معين أخذ رأي جهاة معينة أو استشارة

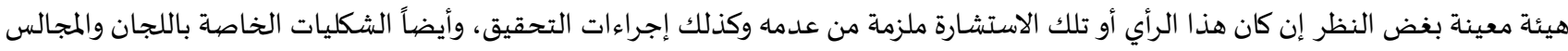

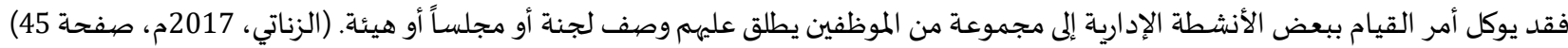

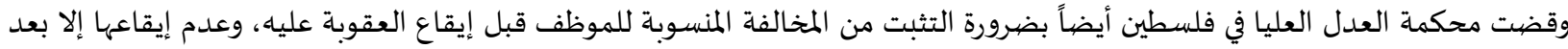

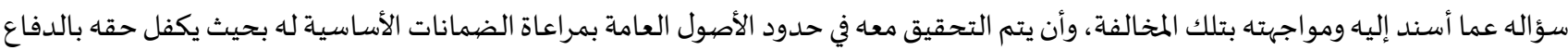

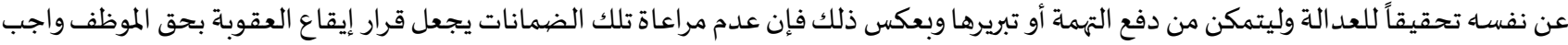

\section{المظهر الخارجي للقرار الإداري}

يقصد بالمظهر الخارجي للقرار الإداري شكل القرار ذاته، والقاعدة أنه ليس للقرار الإداري شكل أو قالب معين يجب أن يصديدر فياه، إلا أن المشرع

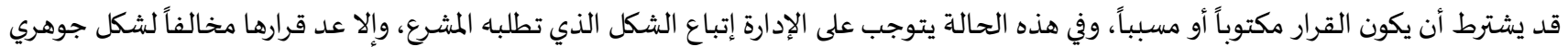

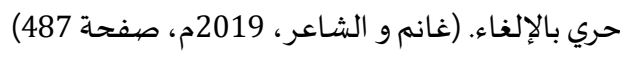
2. - الأشكال غير الجوهرية التي لاتؤثرفي القرار الإداري من المستقر في القضاء الإداري أنه لا يترتب البطلان على كافة مخالفة للشكليات والإجراءات التي لا يتوجب القانون إتباعها والتي لا تؤثر على موضوع

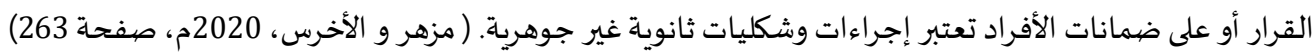
تتمثل الاشكال الثانوية أو غير الجوهرية في تلك الشكليات التي لم يوجب القانون ضرورة إتباعها واحترامها، ولم يرتب البطلان على مخالفتها من جانب الإدارة، وكذلك الاشكال التي لا تؤثر على مضمون القرار ومحتواه بحيث لا ينتج من مخالفتها أي تغيير في محتوى القرار أو الإدارة اتبعتها. إذ أهنا تكون في معظم الأحيان مقررة لمصلحة الإدارة، لذلك فقد استقر القضاء الإداري على أن إغفالها لا يؤدي بالضرورة أي إبطال القرار الإداري

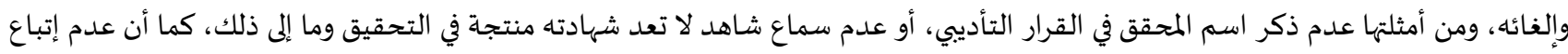

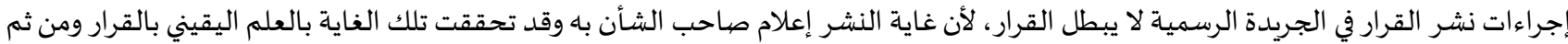

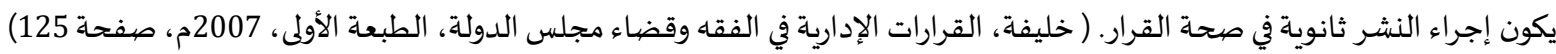

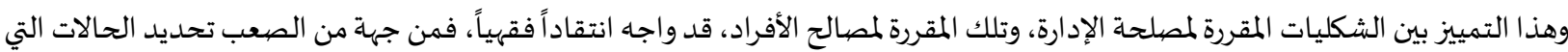
تكون فهيا الأشكال مقررة لمصلحة الإدارة وحدها، ومن جانب آخر فإن هذه الأشكال هي في الحقيقة مقررة لتحقيق الصالح العام، وليس تحقيق صالح 
الإدارة وحدها أو الأفراد وحدهم، بل أن الكومسيون الطبي هو في حقيقته لمصلحة الموظف إلى جانب مصلحة الإدارة، كما أن الطبيعة الموضوعية- العينية

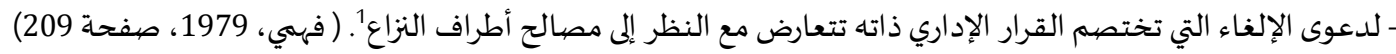

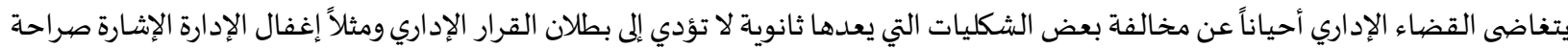

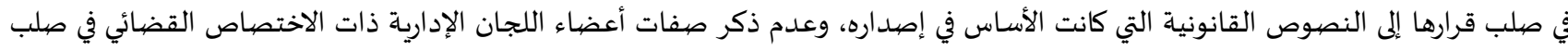
القرارات الصادرة عنها، إن هذا الاتجاه في القضاء يهدف إلى التقليل من الشكليات التي تضر بعمل الإدارة وتقيدها عن أداء وظيفتها إلا أن هذا الاتجاه لا

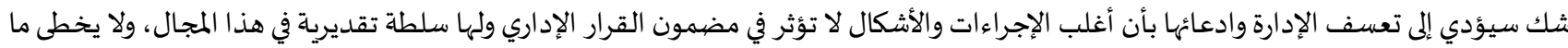

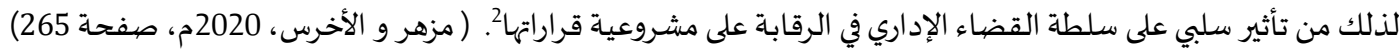

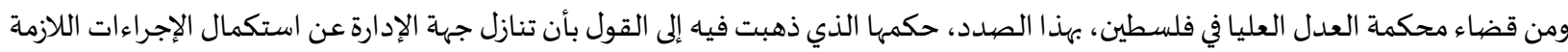

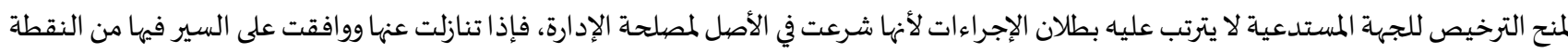
التي توقفت عندها، فإن بقاء القرار المطعون فيه - رفض الترخيص - يغدو والحالة هذه لا مبرر له. (قرارها برام الله رقم 96/38، جلسة 1998/11/3 منشهيه

قرار غير منشور.)

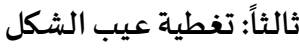

مسألة تغطية عيب الشكل والإجراءات لا تثار إلا بالنسبة للشكل أو الإجراء الجوهري، الذي تم إغفاله، أو تم إجراؤه بصورة غير صحيحة، لأن عيب الشكل والإجراء الجوهري هو الذي يعتد به القضاء ويلغي القرار الإداري بسببه، لكن بالنسبة لعيب الشكل والإجراء غير الجوهري فإن القضياء لا

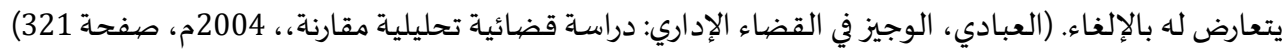

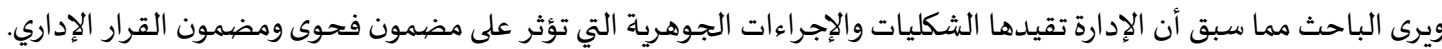

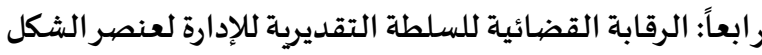

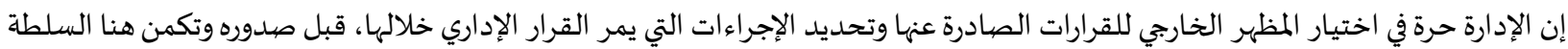

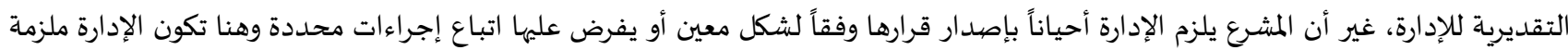

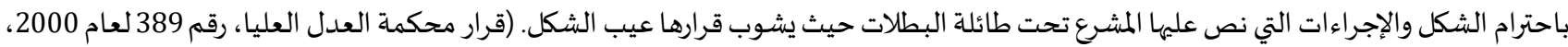

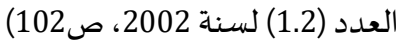

وقد قضت محكمة القضاء الإداري بخصوص الشكل الجوهري بأن:" إغفال الشكل الجوهري بأخذ رأي لجنة شؤون الموظفين يبطل قرار الترقية الذي يصدره الوزير وذلك لأن معرفة رأي اللجنة قبل صدوورها يمكن أن يؤثر على هذا القرار وما انطوى عليه من ترقيات، فهذه اللجنة بمعرفتها بأحوال

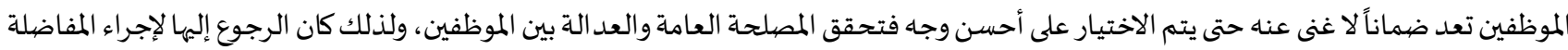
بين المطعون عليهما وبين المدعي وزميله قبل إصدار القرار المطعون فيه أمراً لازماً يترتب على إغفاله إهدار الضمانة التي كفلها القانون من إيجاد اللجنة المذكورة، بجانب الوزير ليستعين برأهها ومشورتها في تعريف أحوال الموظفين وهذا ما يعيب القرار ويبطله". (حكم المحكمة الإدارية في مصر في القضين إنياة

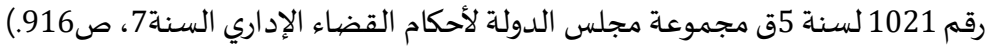
وقضت محكمة العدل العليا في الأردن بوجوب مراعاة الإجراءات المنصوص عليها في القانون بقولها:" وحيث أن كافة الإجراءات والضيمانات التي يتطلها القانون روعي من قبل المجلس فإن قرار المستدعى ضيده-مجلس نقابة المحامين-يكون سليماً من حيث الإدانة" (قرار محكمة العدل العادئ العليا رقم 459

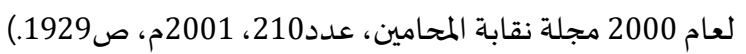

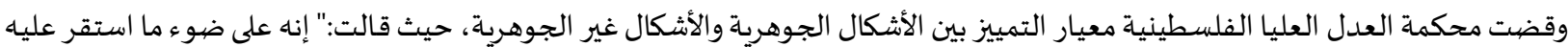
الفقاه والقضاء الإداري بأنه يتوجب على رجل الإدارة أن يراعي الإجراءات التي أوجب القانون مراعاتها قبل إصدار القرار الإداري وأن يفرغ القرار بالشكل

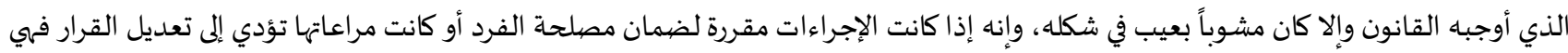

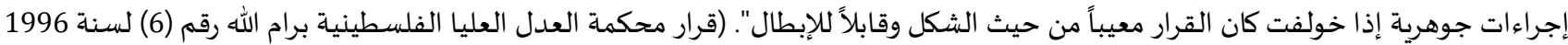

جلسة 1966/11/26م. 1960) ويرى الباحث أنه إذا حدد القانون الأشكال أو الإجراءات التي يلزم اتباعها عند إصدار القرار الإداري، فإن سلطة الإدارة بصيدد هذا العنصر تكون

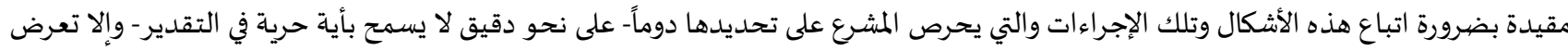
قرارها للإلغاء لتعيبه بعيب الشكل.

1 1 مصطفى أبو زيد فهي، مرجع سابق، ص209.

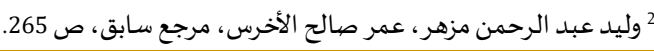


المطلب الثالث: عيب الانحراف في استخدام السلطة

أولاً: التعريف بعيب الانحراف في استخدام السلطة

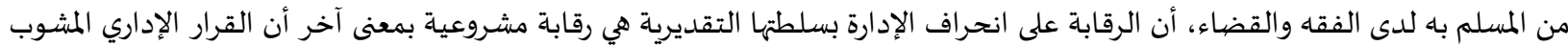
بعيب الانحراف هو قرار إداري غير مشروع، لأن رجل الإدارة تنكر للغاية التي هي ركن أساسي في كل قرار إداري ويكون قد خرج على القانون.

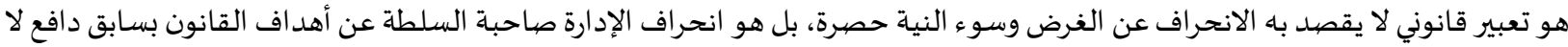

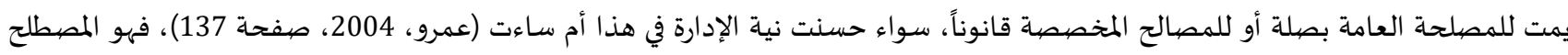
القانوني المعبر عن سوء الإدارة بالمفهوم العام. وقد عرفه بعض الفقاء العربي بأنه "استخد ام الإدارة لسلطتها من أجل تحقيق غاية غير مشروعاة، سواء باء باستهداف غاية بعيدة عن المصلحة العامة،

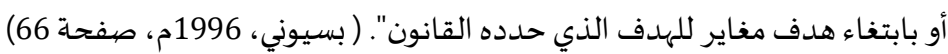
وبهذا يرى معظم الفقه أن التكييف السليم للطبيعة القانونية للانحراف بالسلطة هو أنه مجرد امتداد لعدم المشروعياة. و حماية القضاء الإداري

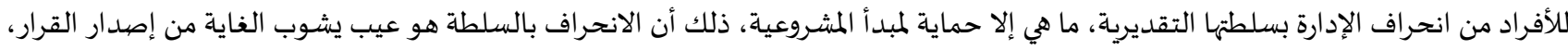

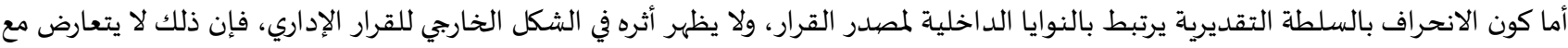

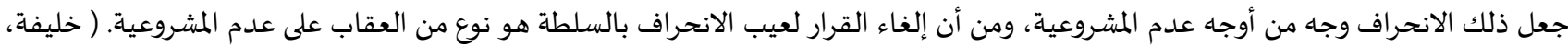

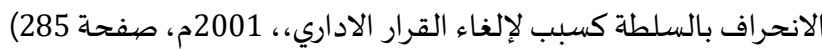

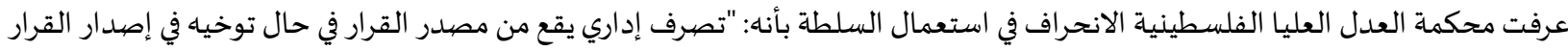

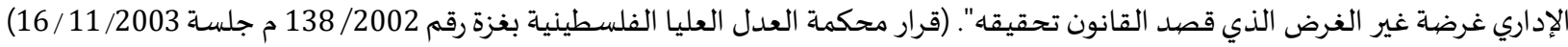

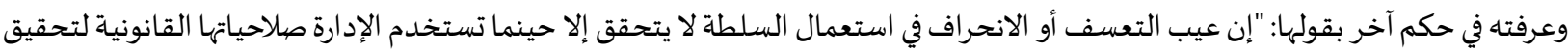

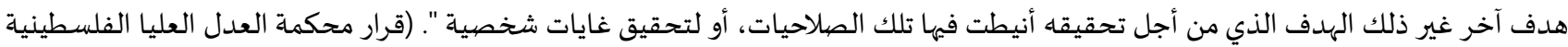

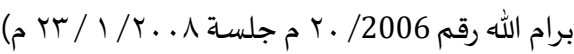
ثانياً: صورعيب الانحراف بالسلطة 1. الانحراف عن المصلحة العامة

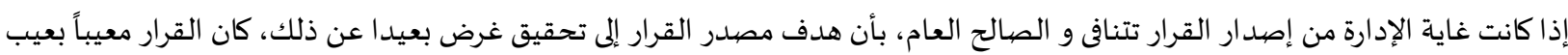

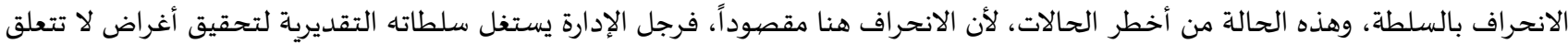

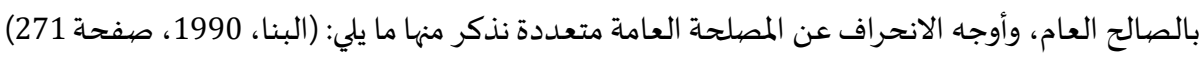
• قد يصدر رجل الإدارة قرارا مستفيدا تحقيق مصلحة شخصية ما، أو تحقيق نفع شخصي يعود للغير، وذلك كفصل موظف بقصيد إخلاء الوظيفة لتعيين موظف آخر فيها، أو تخطي موظف في الترقية وترقية موظف أخرأ أخر أقل منها.

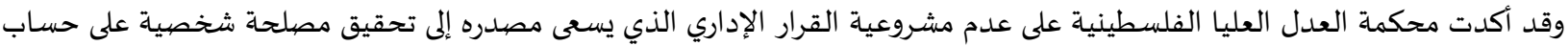

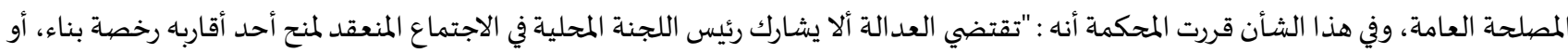

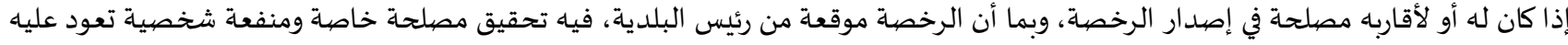

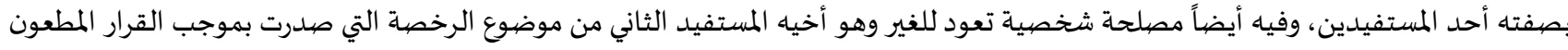
فياه، فإن ذلك يعتبر أمرا غير مشروع ويشكل انحرافا في استخدام السلطة (قرار محكمة العدل العليا الفلسطينية برام الله رقم 2008/ 201 م جلسة

(23/2/2009

• مباشرة السلطة بقصيد الانتقام

حيث تكمن في قيام رجل الإدارة بممارسة سلطاته بقصد الانتقام والتشفي، كأن تقوم الإدارة بفصل أحد الموظفين للتخلص مناه. ومن قضاء محكمة

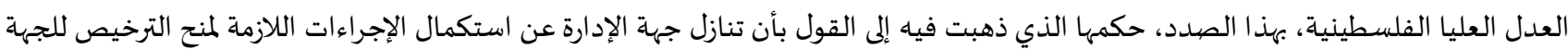
المستدعية لا يترتب عليه بطلان الإجراءات لأها شرعت في الأصل لمصلحة الإدارة، فإذا تنازلت عنها ووافقت على السير فهيها من النقطة التي توقفت عندهاء التهاء

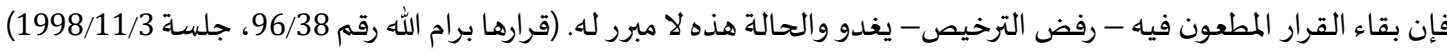
• تصتخدام السلطة لغرض سياسي تتحقق هذه الصورة، بأن تصدر الإدارة قرارا لغاية حزبية بعيدة عن الصالح العام، وهذه الصورة كثيراً ما تتحقق في الدول التي تأخذ بنظام التعددية الحزبية، كأن يصدر أحد الوزراء قرار بفصل موظف لأنه ينتمي إلى حزب سياسي مخالف أو يعتنق مذهباً مغايراً لمذهب الوزير. 
2.

ويعتبر العمل الإداري مشوباً بعيب الانحراف، إذا خرج عن الغاية المخصصة التي رسمت له،، حتى ولو كان الغرض الذي سعت إليه الإدارة يتصل

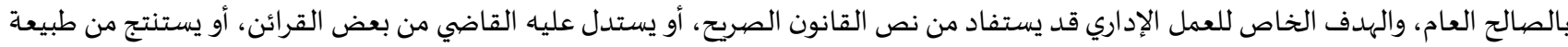

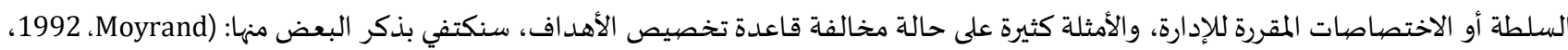

صفحة 160)

استخدام سلطة الضبط الإداري لتحقيق مصالح مالية الانحراف بالإجراءات

ويتحقق، إذا استخدمت الإدارة بعض الوسائل أو الإجراءات لتحقيق غرض تملك تحقيقه و لكن بوسائل أخرى، ومثال ذلك، أن تلجأ الإدارة إلى

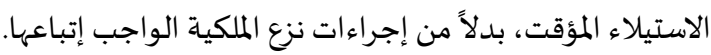

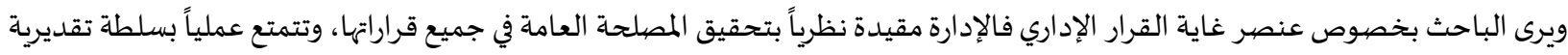
واسعة كونها الجهة التي تملك التقرير بوجود المصلحة العامة من عدمها وتحديد مجال المصلحة العامة والتي تكون إدارية أو اقتصادية أو اجتماعية أو مالية أو سياسية... إلخ، ويتم ذلك كله في ظل رقابة القضاء الإداري. وتحقيق المصلحة العامة مفترض لحق الإدارة وعلى من يدعي العكس إثبات ذلك، وبهذا الخصوص قضيت محكمة العدل العليا:" ونظراً لأن كل قرار

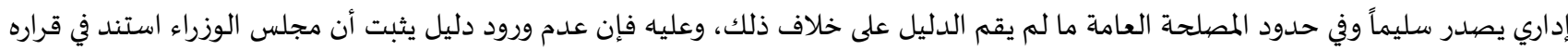
المتضمن إحالة المستدعي على التقاعد للنصوص القانونية بقصد الخروج عن أهداف قانون التقاعد العسكري، وغاياته أو أنه كان مدفوعاً بعوامل

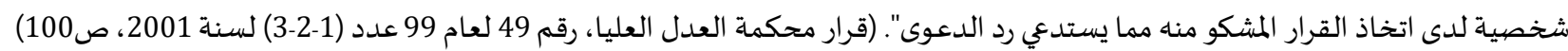
وقضت كذلك:" على رجل الإدارة أن يستهدف في أي قرار يصدره تحقيق الهدف الذي خصصيه القانون لممارسة سلطته التقديرية فإذا خلا قراره

من تحقيق ذلك الهدف كان مشوباً بعيب إسـاءة استعمال السلطة". (قرار محكمة العدل العليا رقم وفي رقابتها على السلطة التقديرية للإدارة في عيب الانحراف قد قضت دحكية إسكمة العدل العليا الفلسطينية بأن:" الإدارة ليست حرة في أن تطلق العنان

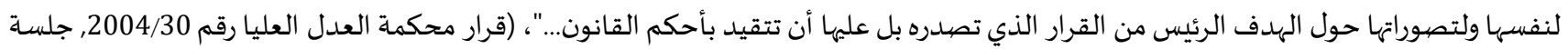

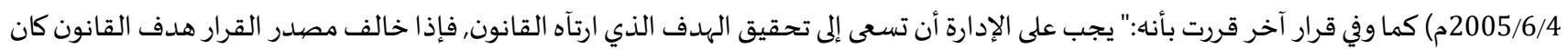

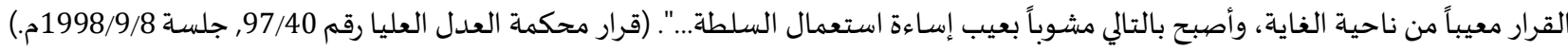

\section{المبحث الثالث: الرقابة القضـائية الداخلية على حدود السلطة التقديرية}

يرتبط الاختصاص المقيد للإدارة بفكرة المشروعية ارتباطاً وثيقاً، ولذلك فإن الإدارة تخضع في ممارسته للرقابة القضائية، حيث أن مضمون الرقابة

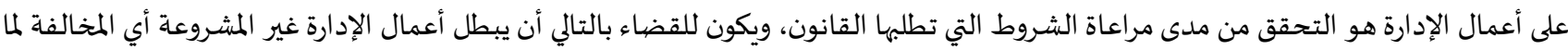
نص علياء القانون.

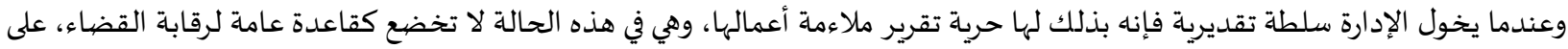

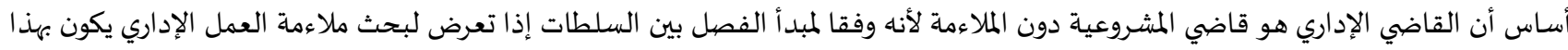

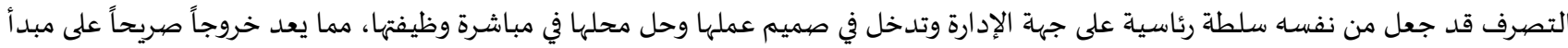

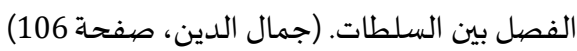

$$
\text { ألمطلبً: التعريف بالول: عيب السببب }
$$

السبب هو الحالة الواقعية أو القانونية السابقة على القرار والتي تظهر فتدفع جهة الإدارة إلي إصدار القرار. (حجازي، 2001، صفحة 8)

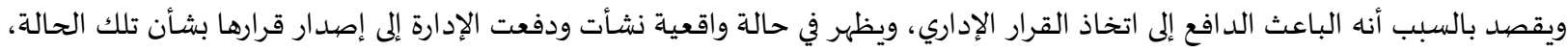

$$
\text { وبذلك يكون السبب عنصراً سابقاً وخارجاً عن القرار. }
$$

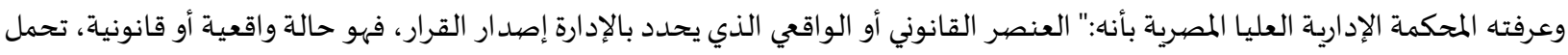

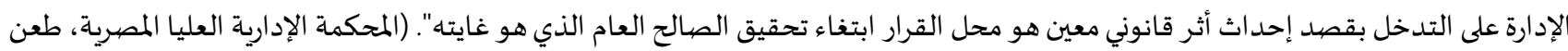

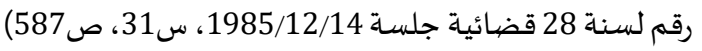

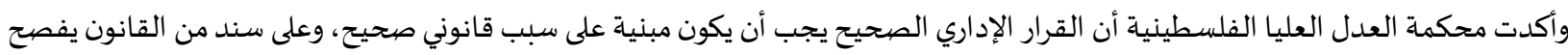

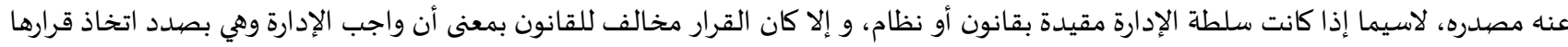

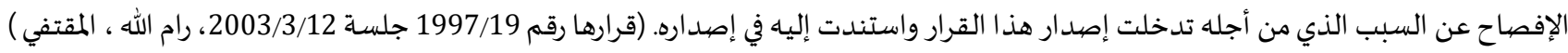


وفي تعريف أخر بأنه:" فهو يعني عدم مشروعية السبب -الأسباب- الذي بني عليه القرار الإداري، إما لعدم وجود الحالة القانونية أو الواقعية

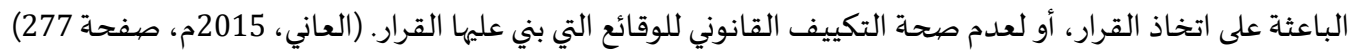
ويقصد بالسبب أنه الباعث الدافع إلى اتخاذ القرار الإداري، ويظهر في حالة واقعية نشأت ودفعت الإدارة إلى إصدار قرارها بشأن تلك الحالة،

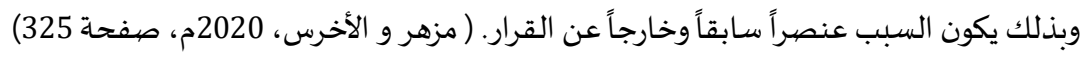
ونحن من جانبنا نعرف عيب السبب بأنه انعدام الواقعة المادية أو القانونية التي يقوم عليها القرار لعدم وجودوها أوسا أو عدم صححة التكييف القانوني للوقائع. ثانياً: شروط صحة السبب حتى يعتد بصحة وسلامة القرار الإداري فإنه يشترط في سبباه مجموعة من الشروط اللازمة لذلك، وفيما يلي نتناوله على النحو التالي:

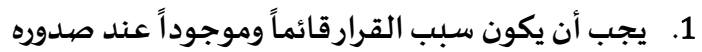
ومعنى ذلك فإنه يجب أن تكون الحالة الواقعية أو القانونية التي دفعت نحو إصداردار القرار الإداري قائمة وموجودودة عند اتخاذه، بحيث إن إن لم تكن

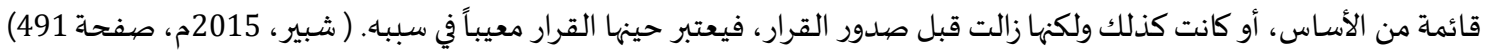
وهذا متفق مع القاعدة العامة التي تقضي بأن تاريخ صدور القرار هو الوقت الذي يجب الرجوع إليه لتقدير مشروعية أو عدم مشروعية القرار

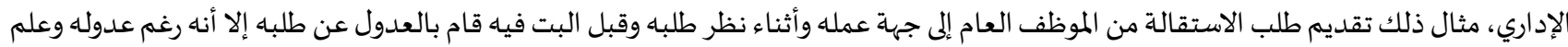
جهة عمله باه أصدرت قرارها بقبول استقالته، ففي هذه الحالة يكون قرار قبول الاستقالة غير قائم على سبب يبرر صدوروه.

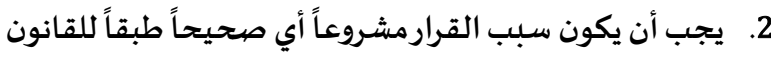

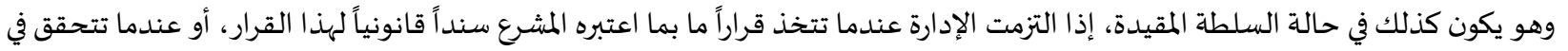

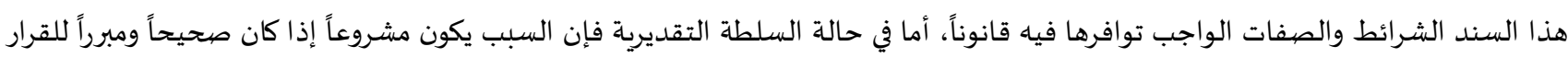

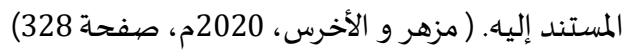

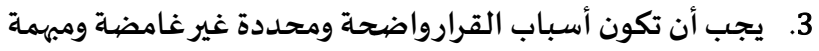

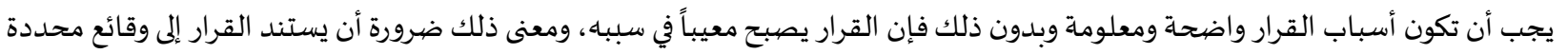
ومعروفة وليست مبهمة ومجهولة، حتى يستطيع صاحب الشأن تحديد موقفه منها، ولكي يتمكن القضياء من إعمال رقابته على ركن السبب في القرار

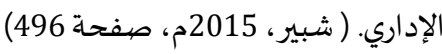

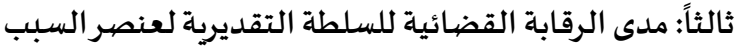

رقابة القضياء على الوجود المادي للوقائع: أن القرار الإداري حتى يكون مشروعاً في سببه يجب أن تستند الإدارة إلى سبب أو أسباب موجودة

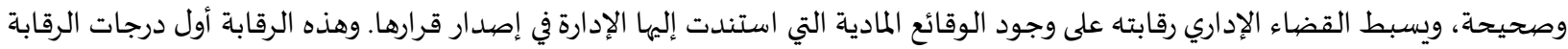

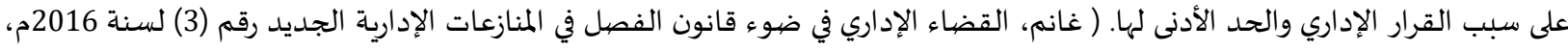

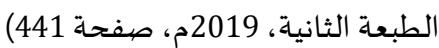
ويعترف القضاء الإداري بسلطة الرقابة على صحة الوجود المادي للوقائع، فهو يقوم برقابته على الجانب ليتأكد من صحة الوقائع المبررة للقرار

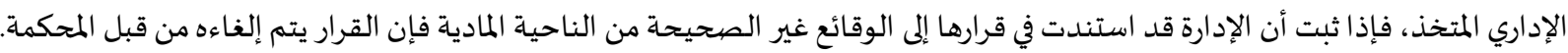
فالرقابة القضائية على صحة الوجود المادي للوقائع التي يقوم عليها القرار الإداري بوجه عام، الحلقة الأولى للرقابة على عنصر السبب، ودون

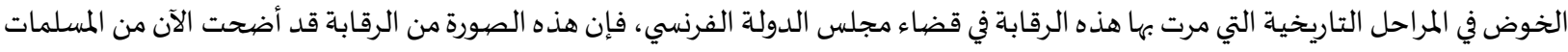
في الفقه، والقضاء الإداريين العربي، والمقارن على السواء، وهي تتجسـد باختصيار في بحث القضاء الإداري عما إذا كانت الوقائع التي اتخذتها الإدارة

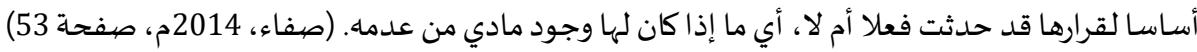

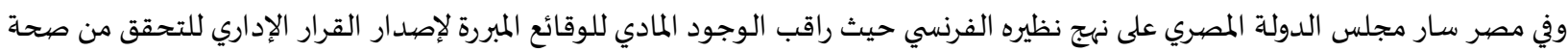

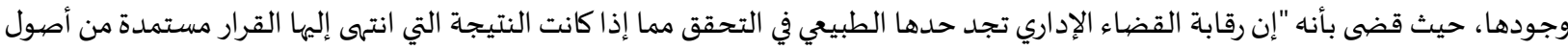

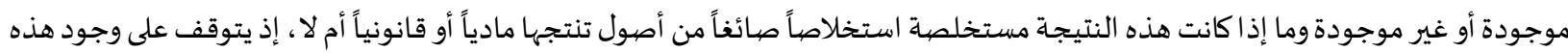

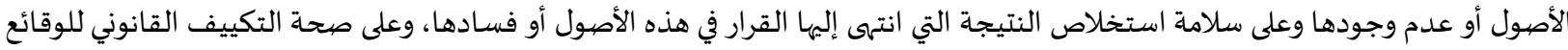

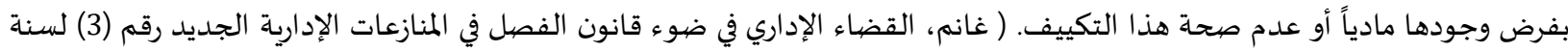

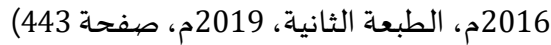
ونجد في حكم للمحكمة الإدارية المصرية قد جاء فيها على أنه:" رقابة القضياء الإداري لصحة الحالة الواقعية أو القانونية التي تكون ركن السبب التباء تجدد حدها الطبيعي في التحقق مما إذا كانت النتيجة التي انتهى إليها القرار مستخلصة استخلاصاً سائغاً من أصول تنتجها مادياً أو قانونياً - فإذا

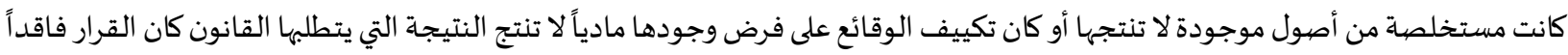


اركن من أركانه وهو ركن السبب - بحث ذلك يدخل في صميم اختصاص المحكمة للتحقق من مطابقة القرار للقانون والتأكد من مشروعيته".

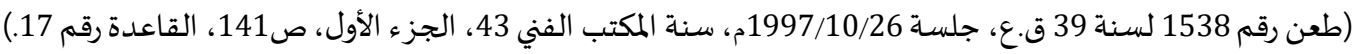

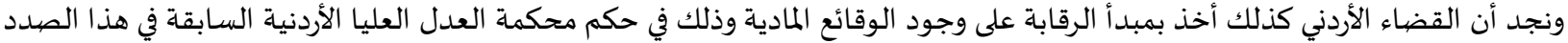

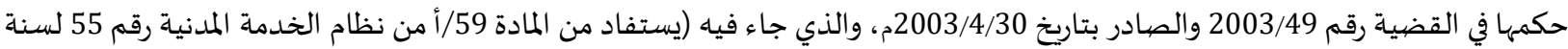

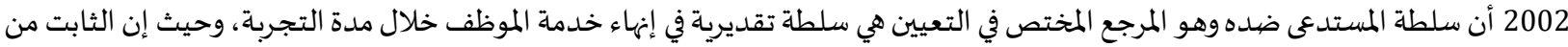

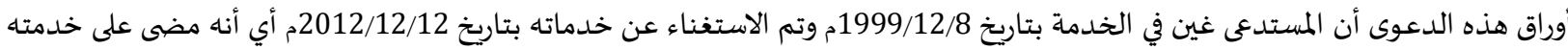

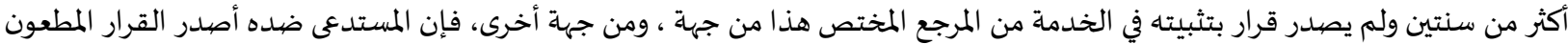

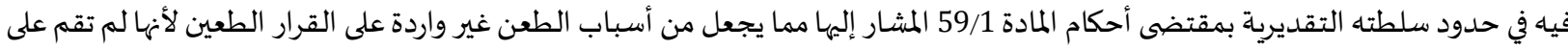

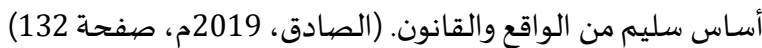

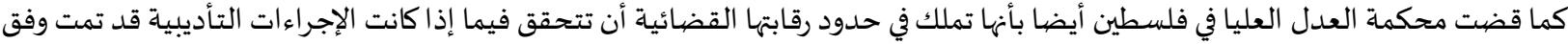

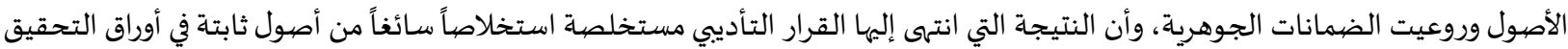

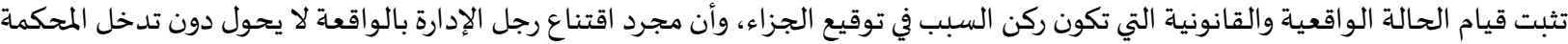

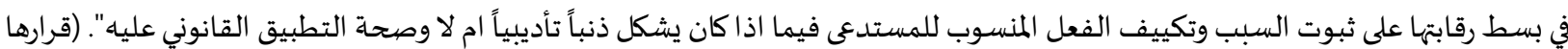
رقم 97/10 جلسة 2003/12/16، رام الله، المقتفي.)

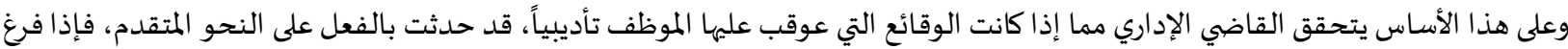

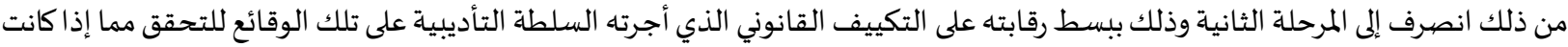

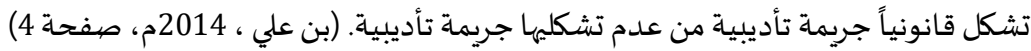

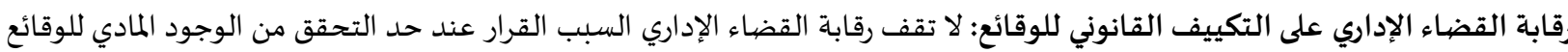

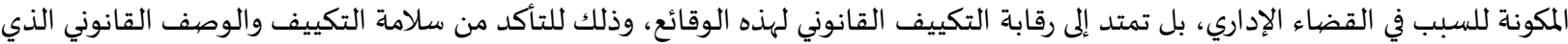
أنزلته الإدارة على الوقائع المادية في إصداء الإداري قرارها.

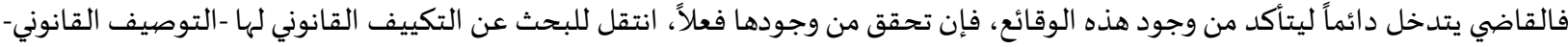

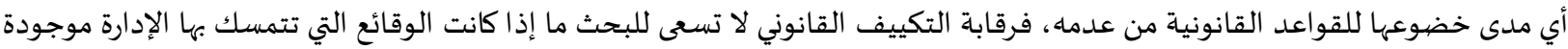

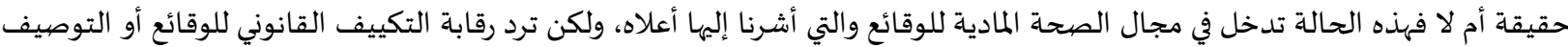

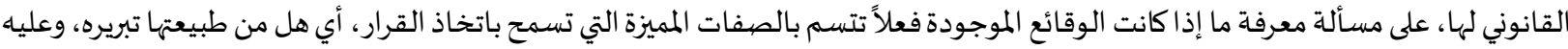

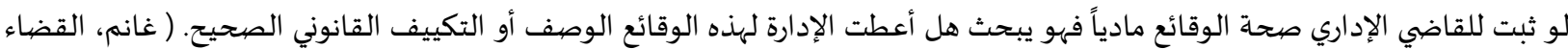

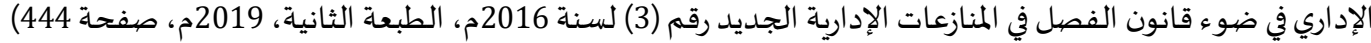

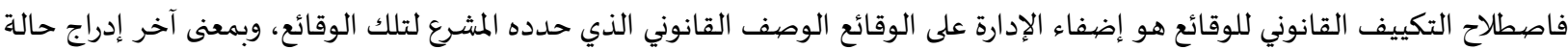

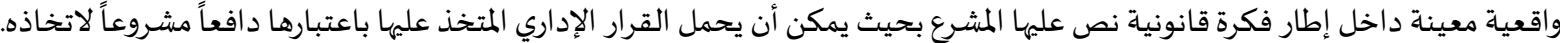

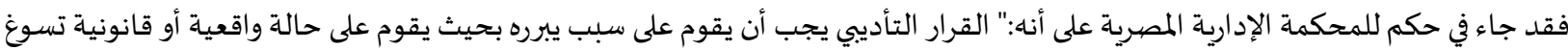

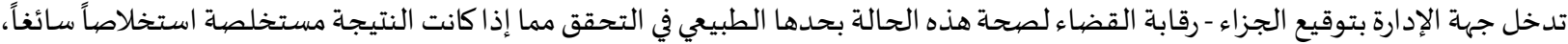

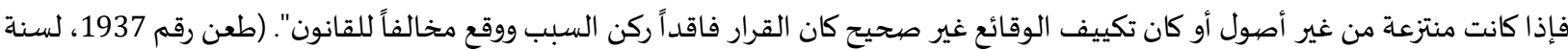

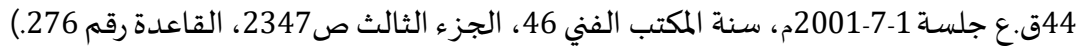

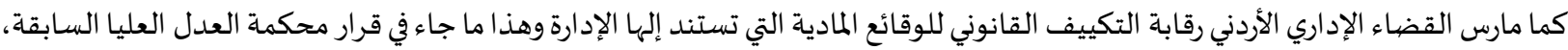

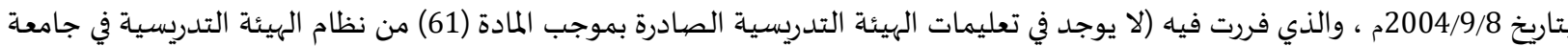

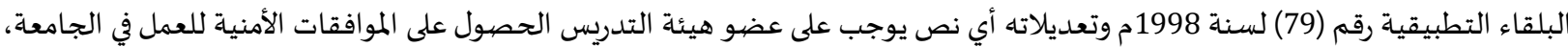

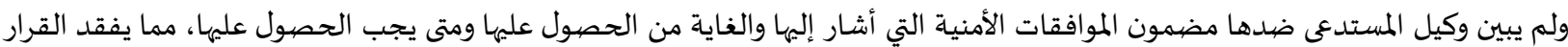

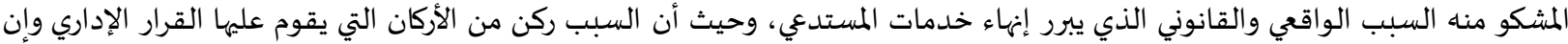

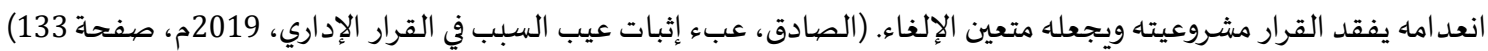

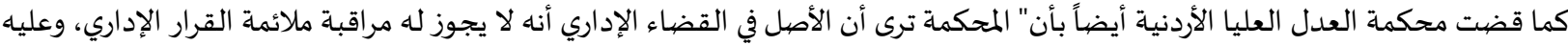

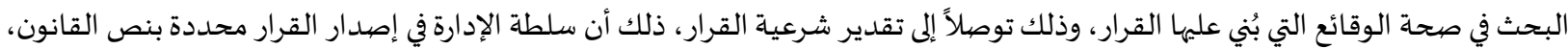

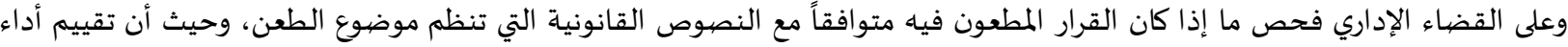

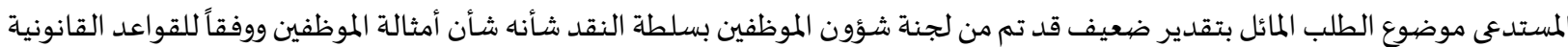


في لائحة الى سلطة النقد ......... وما تقدم يكون طلب المستدعي غير قائم على أساس القانون والحقيقة". (قرارها رقم 2003/141 جلسـة 2004/6/8،

ثالثاً: الرقابة على مدى ملائمة القرار

يجمع الفقه الإداري على أن هذه الصورة من الرقابة لا يمارسها القضاء الإدارئ عاري على القرارات الإدارية ، إلا على سبيل الاستثناء من القاعدة العامة في رقابته على مشروعياة الأعمال الإدارية، والتي تقتصر في الأصل، على التحقق من صحة الوجود المادي للوقائع، ومن سلامة تكييفها القانوني، ولا تتعداه

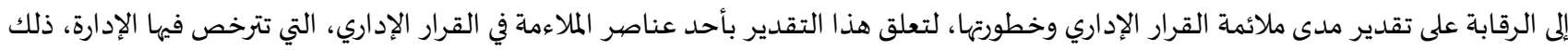

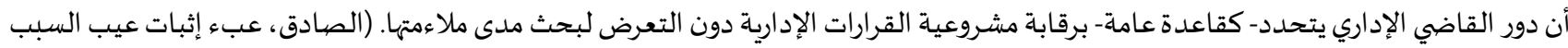

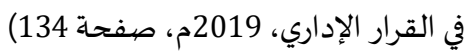

الأصل أن رقابة قاضي الإلغاء تنصب على على مشروعية القرار الإداري دون النظر في ملائمته، لدخول الملائمة بطبيعتها في تقدير الإدارة، إلا أنه حينما

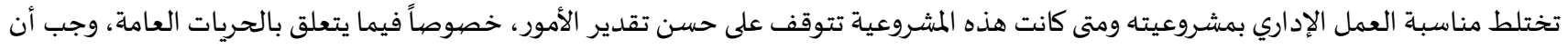

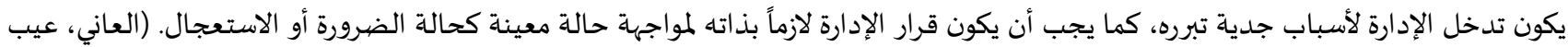

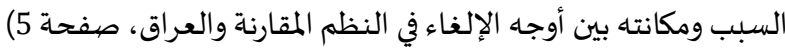
ويعني بهذه الرقابة أنه يجب على القاضي الإداءئ فئي الإمتناع عن مراجعة الإدارة في تقدريها لأهمية وخطورة الحالة الواقعية التي استندت إليها بوصفها

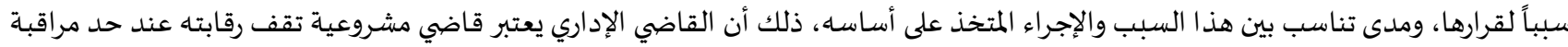

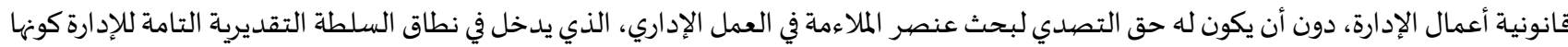
هي التي تدرك شؤونها وحاجاتها وما تتطلباء من تصرفات تتخذ في الوقت المناسب وبالكيفية والأهمية المناسبة، وتبعاً لذلك وقفت رقات رقابة مجلس الدولة

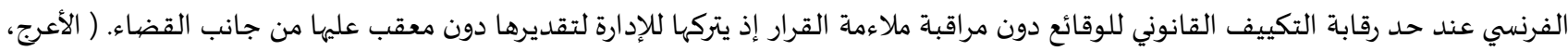

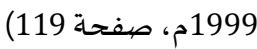

فقد جاء في حكم للمحكمة المصرية بأن:" من المبادئ العامة للمسؤولية التأديبية تقدير خطورة ما يثبت من قبل العامل من مخالفات أو جرائم

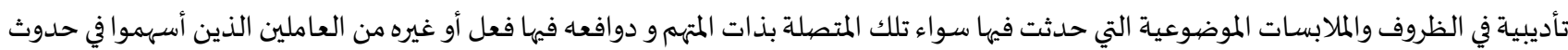

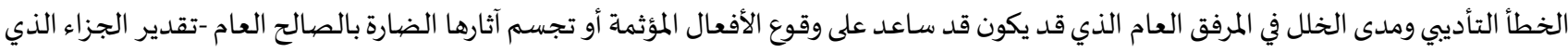

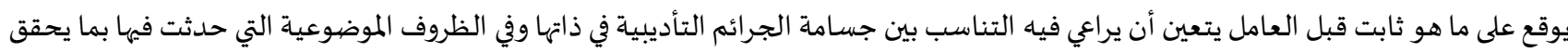

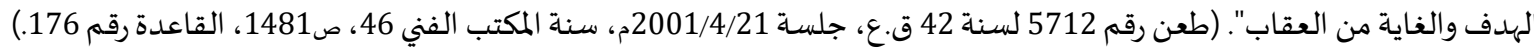

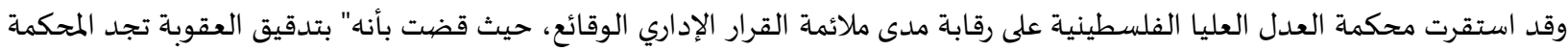
بأها لا يوجد غلو في العقوبة، ولما كانت محكمة العدل العليا تفرض رقابتها على صحة الإجراءات وعلى مدى ملائمة العقوبة مع المخالفة المنسوبة للمحامي

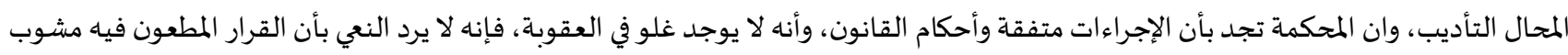
بعيب التعسف باستعمال السلطة حيث أن الأصل في القرار الإداري صدورهه بريء في بواعثه وأهد افه والنعي عليه بإساءة استعمال السلطة مؤداه انحرافهاه

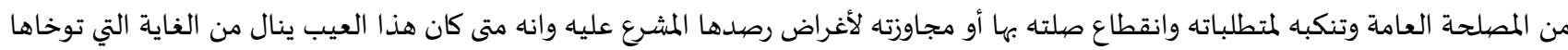

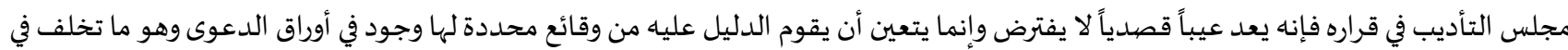

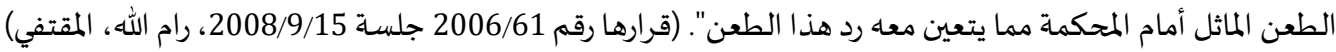

المطلب الثاني: عيب المحل

أولاً: التعريف بعيب المحل

يقصد بعيب المحل في القرار الإداري هو الأثر القانوني الذي تتجاه إرادة جهة الإدارة إلى ترتيبه، ويتمثل هذا الأثر القانوني في إنشاء المراكز القانونية

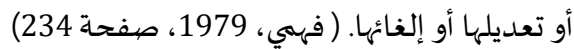

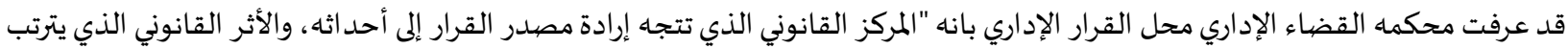
عليه يقوم مباشرة وفي الحال وهذا الأثر هو انشاء حالة قانونية جديدة أو تعديل في مركز قانون القائم او إلغاؤه". (حكم محكمة القضاء الاداري في

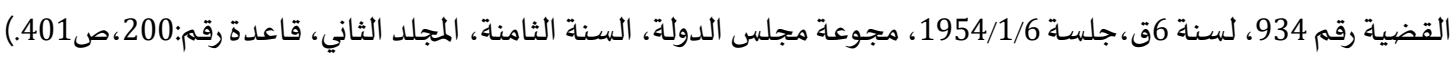
وعيب مخالفة القانون هو العيب الذي يلحق أساساً المحل في القرار الإداري، لمخالفتـ القواعد القانونية الموضوعية إذ يشترط لصحة ومشروعية القرار الإداري أن يكون الأثر القانوني الذي يحدثثه متفقا مع القواعد القانونية، فإذا كان هذا الأثر مخالفاً للقاعدة القانونية كان القرار معيباً في محله وجديراً بالإلغاء. أما الشرط الثاني فيقتضي أن يكون محل القرار ممكناً، من الناحية الواقعية والقانونية، فإذا استحال هذا المحل قانونا أو واقعا فإن القرار الإداري

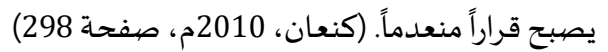


ويقصد بعيب المحل أو عيب مخالفة القانون، أن يخالف محل القرار الإداري إحدى القواعد القانونية وتستوي في ذلك القواعد المدونة كالدستور والتشريع العادي أو الفرعي أو غير المدونة المستمدة من المغاب العرف والمبادئ المبادئ العامة للقانون.

ثانياً: صور مخالفة القواعد القانونية

بينت محكمة القضياء الإداري في مصر الصهور المختلفة لمخالفة القانون بقولها:" إن مدلول مخالفة القانوانون يشمل كل مخالفة القواعد القانونية

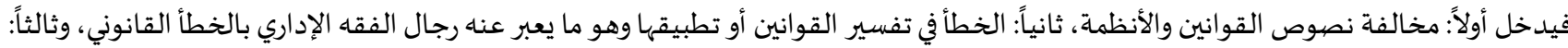

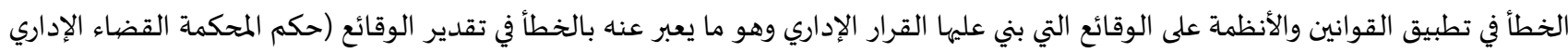

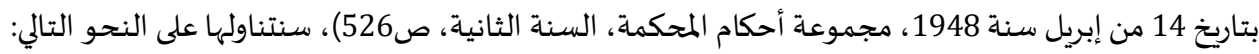

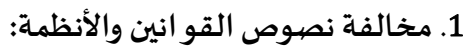

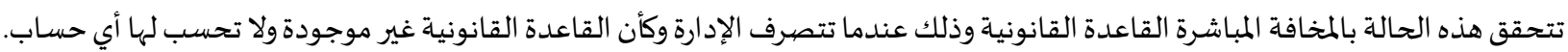

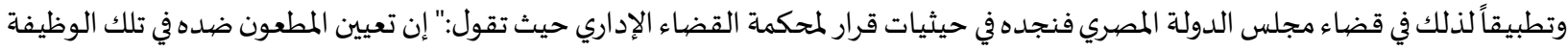

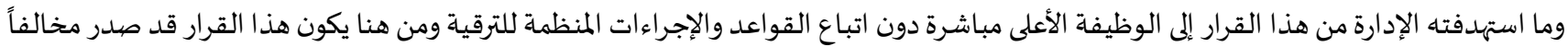

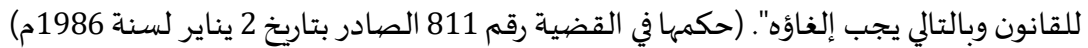

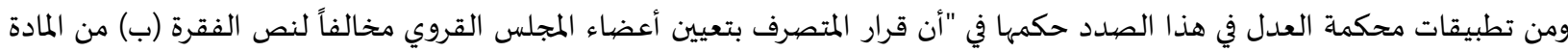
الخامسة من قانون إدارة القرى التي توجب انتخاب أعضاء المجلس القروي وفق الطريقة التي يقررها متصرف اللواء". (حكم محكمة العدل العليا في

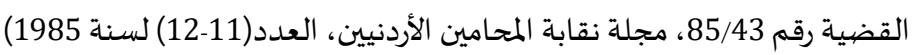
وتطبيقً لذلك ذهبت محكمة العدل العليا الفلسطينية الى أنه " لا يجوز للإدارة مخالفة حكم القانون، بل ينبغي توافق عملها ما صحيح نصهوص

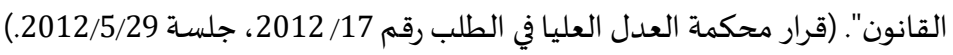
2. الخطأ في تفسير القو انين والأنظمة

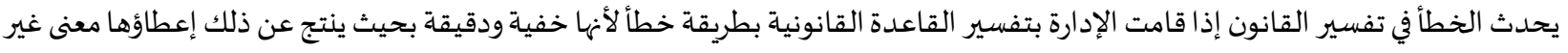
المعنى الذي قصده المشرع أو التفسير الذي لم يتجها إليه قصديده. وتطبيقاً لذلك في القضياء المصري فقد أكدت محكمة القضاء الإداري" أن القرار المطلوب إلغاؤه لا يعد مفسراً للقرار الأول إذ لا وجه التفسير إلا الا

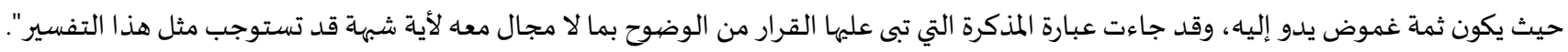

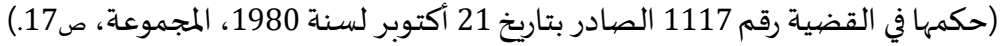

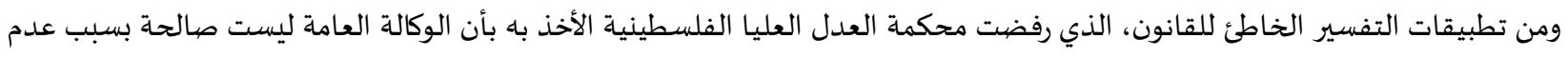

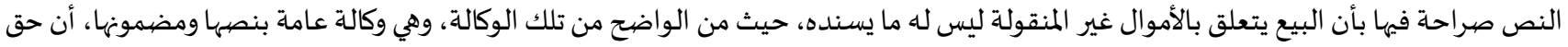

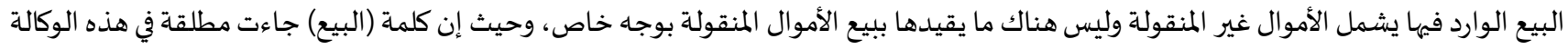

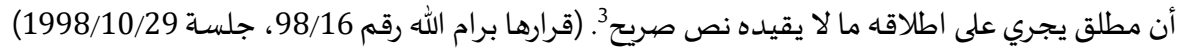
3. الخطأ في تطبيق القاعدة القانونية يقصيد بالخطأ في تطبيق القانون، مباشرة الإدارة للسلطة التي منحها القانون إياها بالنسبة لغير الحالات الواقعية التي نص عليها القانون، أو دون توافر الشروط التي حددها القانون لمباشرتها، وهنا تأتي مهمة القضاء الإداري الذي عليه أن يراقب الوقائع ويتحقق من سلامتها حتى يصل إلى مشروعية

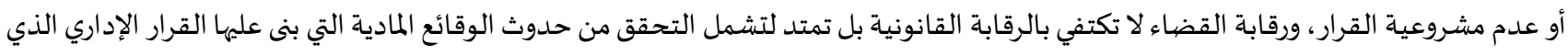

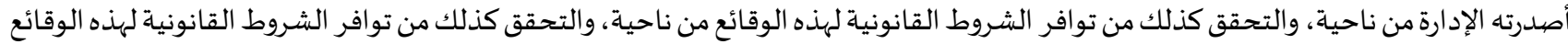
من ناحية أخرى. في الأخير فإننا نصل إلى أن طبيعة الرقابة القضائية على السلطة التقديرية للإدارة، هي رقابة مشروعية أصلا وليست رقابة ملاءمة، فالقاضي الإداري في بداية تصديه لفكرة السلطة التقديرية، كان يتجنب كل رقابة تخص إنصا أو تتعلق بالجانب التقديري للإدارة، لأنه كان يرى أن ذلك يتناقض ومبدأ الفصل بين السلطات وفكرة السلطة الرئاسية.

الخاتمةة:

ننهي إلى أن الإدارة تخضع في مباشرتها لأعمالها وتصرفاتها لمبدأ المشروعية، فتتمتع الإدارة بقسط من الحرية في حالة السلطة التقديرية، وتتصرف

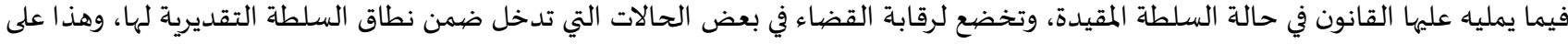
خلاف الرقابة القضائية الدائمة على التصرفات التي هي من قبيل السلطة المقيدة لها، فالدول التي تمنح الإدارة الحرية في تقدير ما هو ملائم لعملها

1998/10/29 قرارها برام الله رقم 98/16، جلسة 
الإداري وفق قيود وضوابط المصلحة العامة واتفاقاً مع مبدأ المشروعية تعتبر دولة قانونية غير استبدادية وأقدر من غيرها التي تطبق فيها السلطة المقيدة

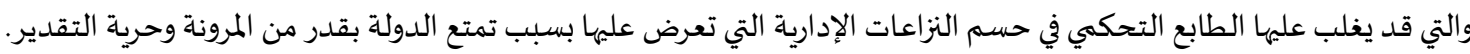

أولاً: النتائج:

الأصل أن القضاء لا يمارس رقابة على السلطة التقديرية إذا كانت في حدود القانون.

السلطة التقديرية وسيلة قانونية لتحقيق مبدأ المشروعية فهي ليست خروجاً عنها.

غالبية تصرفات وقرارات إدارية تجمع بين الصنفين سلطة تقديرية وسلطة مقيدة، فليس هناك ما يعرف بالسلطة المقيدة على الاطلاق أو السلطة

التقديرية، فقرار الإدارة الواحد يتضمن طابع تقديري ومقيد في نفس الوقت.

السلطة التقديرية للإدارة تكمن في عنصر السبب والمحل والغاية أما السلطة المقيدة فتكون في الاختصاص والشكل.

تعتبر رقابة الملائمة عنصر من رقابة المشروعية، لذلك فهي ليست خروجاً عنها.

رقابة الإدارة على الأعمال التقديرية للإدارة رقابة مشروعية دون أن تمتد إلى ملاءمتاه.

وجود قضاء متخصص يمارس الرقابة على أعمال الإدارة يمثل ضرورة ملحة لحقوق وحريات الأفراد في مواجهة تعسف السلطة.

ثانياً: التوصيات:

العمل على إنشاء لجان رقابية داخل جميع الهيئات والمؤسسات الإدارية وتفعيل دورها في الرقابة الداخلية للتأكد من مدى مطابقة أعمال الإدارة

لمبدأ المشروعياة.

ضرورة أن تمارس الإدارة سلطتها التقديرية في أفضل الظروف.

ضرورة تنظيم المشرع الاردني لحالات الاختصاص المقيد والسلطة التقديرية.

نأمل من الإدارة ضرورة استهدافها للمصلحة العامة عند استعمالها للامتيازات المقررة لها بموجب القانون لاسيما السلطة التقديرية.

ضرورة إنشاء قضياء إداري متخصص ذو صلة بالعمل الإداري بشكل قريب ومباشر.

المراجع:

أولاً: الكتب والرسائل العلمية:

1. الأعرج، ميسون جريس عيسى (1999). عيب السبب في القرار الإد/ري، دراسة مقارنة وتطبيقية في الأردن. رسالة ماجستير، الجامعة الأردنية، عمان،

2. بسيوني، عبد الغني (1996). القضياء الإداري. منشأة دار المعارف، الإسكندرية.

3. بسيوني، عبد الله (د.ت). النظرية العامة في القانون الإداري.

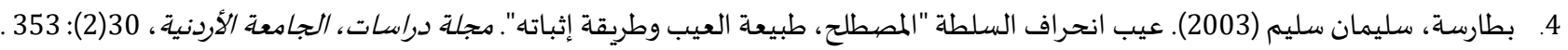
5. بعلوشة، شريف (2010). دعوى الغاء القرار الإد/ري، دراسة تحليلية مقارنة. رسالة ماجستير غير منشورة، جامعة الأزهر، فلسطين.

6. البنا، محمد عاطف (1990). الوسيط في القضياء الإد/ري. دار الفكر العربي، القاهرة.

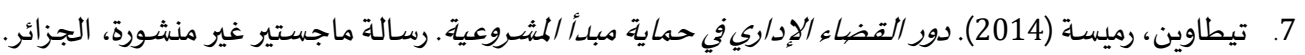

8. الجبوري، محمود خلف (د.ت). القضاء الإد/ري. الطبعة الأولى، دار الثقافة للنشر والتوزيع، عمان. 9. الجرف، طعيمة (1973). القانون الإد/ري- دراسة مقارنة-. القاهرة.

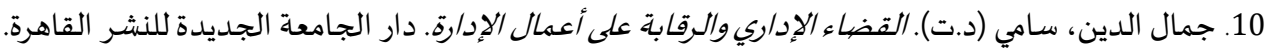

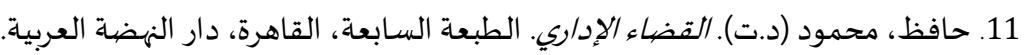

12. حجازي، رضا (2001). الرقابة القضائية على ركن السبب في إجراءات الضبط الإداري، درابسة مقارنة رسالة دكتوراه. جامعة القاهرة.

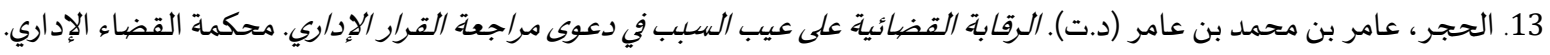

14. حسن، عبد الفتاح (1971). التعويض في القانون الإد/ري والإد/رة العامة. القاهرة.

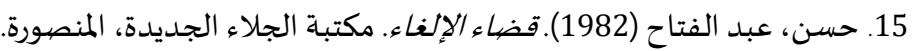

16. حسين، محسن الجواد (1953). بين سلطة الإدارة التقديرية واختصاصها المقيد. محجلة مجلس الدولة، ، السنة 04، القاهية الاهرة.

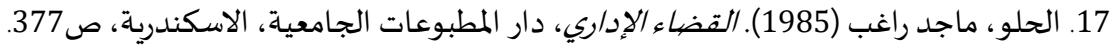

18. خليفة، عبد العزيز عبد المنعم (2001). الانحراف بالسلطة كسبب لإلغاء القرار الإداري. الطبعة الأولى، الإسكندرية، دار الفكر الجامعي. 
19. خليفة، عبد العزيز عبد المنعم (2007). القرارات الإد/رية في الفقه وقضياء مجلس الدولة. الطبعة الأولى، دار الكتب المصبرية، مصر.

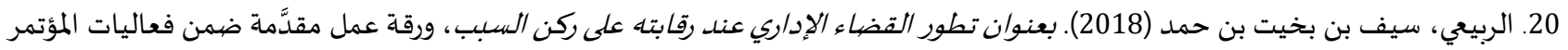
الثامن لرؤساء المحاكم الإدارية العربية المنعقد بالمركز العربي للبحوث القانونية والقضيائية بالعاصيمة اللبنانية بيروت خلال الفترة: من 24 إلى 2018/9/26م، محكمة القضياء الإد اري، سلطنة عمان. 21. الزناتي، مصطفى أسامة (2017). عيب الشكل والاجراء/ت وأثره على صحة القرار الإداري في القانون الفلسطيني. دراسة تحليلية، رسالة ماجستير،

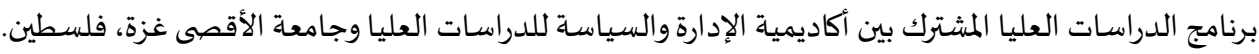

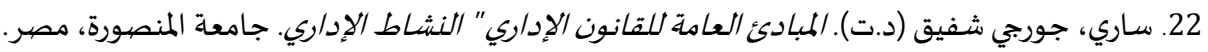

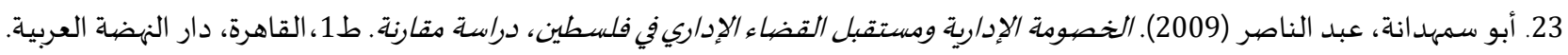

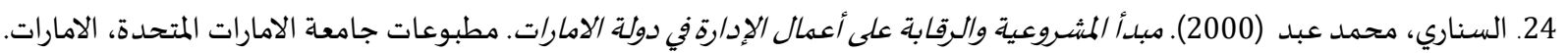
25. شبير، محمد سليمان نايف (2015). القضياء الإد/ري في فلسطين. الطبعة الأولى، دار النهضية العربية، القاهرة.

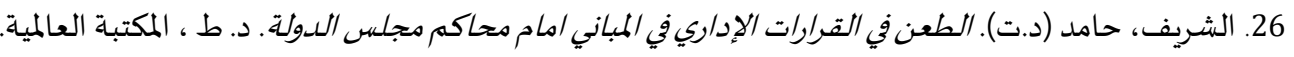
27. شطناوي، علي خاطر (2004). موسوعة القضاء الإداري، الجزء الأول. مكتبة دار الثقافة للنشر والتوزيع، عمان، الطبعة الأولى، الإصدار الأول، ص.751.

28. شيحا، إبراهيم عبد العزيز (1994). القضياء الإداري اللبناني ومجلس شورى الدولة اللبناني. الدار الجامعية، بيروت. 29. الصادق، أحمد فرج (2019). عبء إثبات عيب السبب في القرار الإد/ري. مجلة دراسات وأبحاث المجلة العربية في العلوم الإنسانية والاجتماعية، لئل

30. صادق، علي (2008). دعوى الإلغاء في القضياء الإد/ري الفلسطيني. معهد البحوث للدراسات العربية، القاهرة.

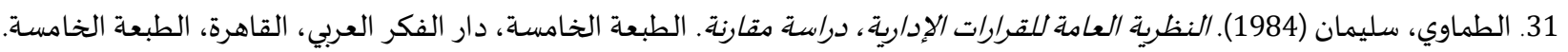

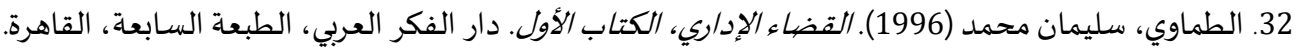

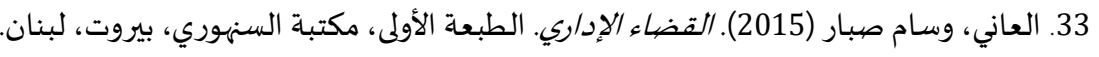

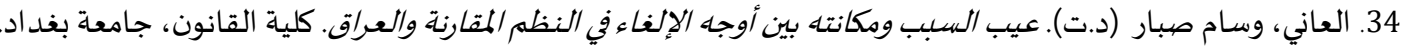
35. العبادي، محممد وليد (2004). الوجيزفي القضاء الإد/ري: دراسة قضائية تحليلية مقارنة. دار المسار للنشر والتوزيع، الطبعة الأولى، المفرق، الأردن. 36. عبد الحميد، بن علي (2014). الرقابة القضائية على ركن السبب في القرار التأديبي. مجلة البحوث القانونية ، العدد العبد الثاني.

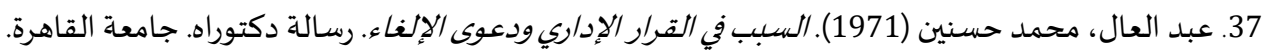
38. عبد الله، عبد الغني بسيوني (1990). القانون الإد/ري. الدار الجامعياة، الإسكندرية. 39. عبد الوهاب، محمد رفعت (2003). القضياء الإد/ري. الكتاب الأول، منشورات الحلبي الحقوقياة، بيروت.

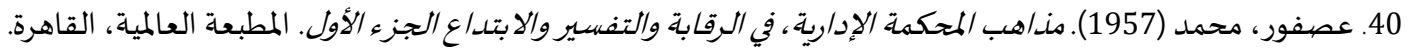

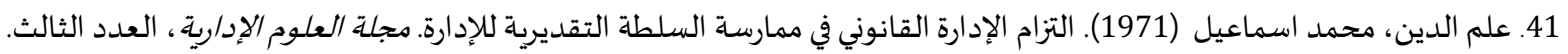

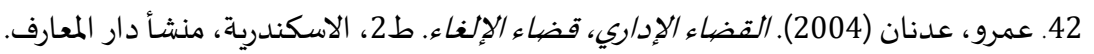

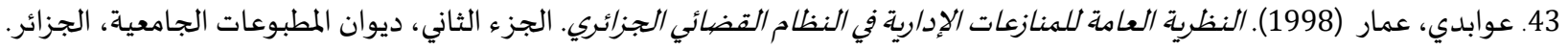
44. غانم، هاني عبد الرحمن (د.ت). القضاء الإداري في ضيوء قانون الفصل في المنازعات الإدارية الجبديل.

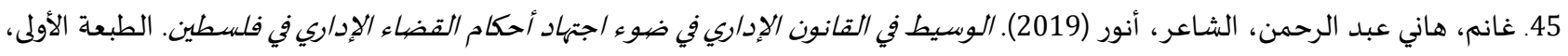
مكتبة نيسان للطباعة والتوزيع.

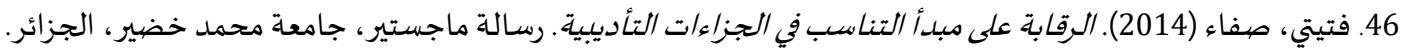

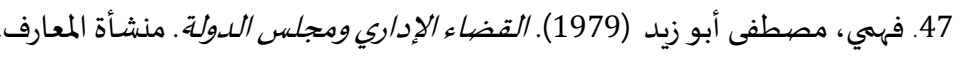
48. كنعان، نواف (2010). القانون الإداري، الكتاب الثاني،" الوظيفة العامة، القرارات الإد/رية، العقود الإدارية، الأموال العامة" . الطبعة الأولى، دار الثقافة للنشر والتوزيع، عمان. 49. ليو، مازن راضي (2008). الوجيز في القانون الإد/ري. د. ط، دنمارك، منشورات الاكاديمية العربية. 50. مزهر، وليد عبد الرحمن، الأخرس، عمر صالح (2020). الوجيز في القضاء الإد/ري في فلسطين. الطبعة الأولى، مكتبة نيسان للنشر والتوزيع، غزة.

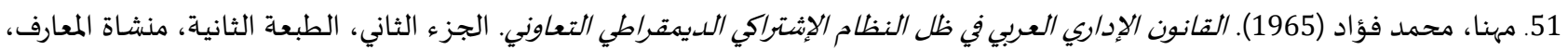

الإسكندرية، ص1143. 
52. نجم، أحمد حافظ عطية (1982). السلطة التقديرية للإدارة ودعاوي الانحراف بالسلطة في الأحكام الحديثة لمجلس الدولة الفرنسي. مجلة العلوم الإد/رية ، 23(1)، القاهرة.

53. اليازجي، منيرة عمر (2017). الرقابة القضائية على السلطة التقديرية للإدارة في فلسطين: دراسة تحليلية مقارنة. رسالة ماجستير، الجامعة الإسلامية بغزة.

ثانياً: المراجع الأجنبية:

1. Alain Moyrand (1992). Le droit administratif.L'hermès, P160.

2. Jacqueline Morand -Devil (1999). Cours de droit Administrative. Montchrestien 6e edition. P. 278. 


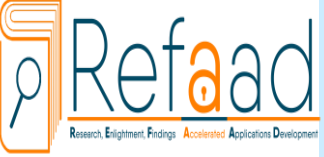

www.refaad.com

$$
\text { المجلة الدولية للدراسات القانونية والفقهية المقارنة }
$$

International Journal of Legal and Comparative Jurisprudence Studies (LCJS)

Journal Homepage: https://www.refaad.com/views/LCJS/Home.aspx ISSN: 2708-6607(Online) 2708-6593(Print)

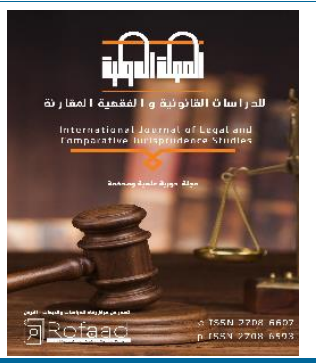

\title{
Judicial control over the discretionary power of management
}

\author{
Walid Abdul Ruhman Mezher
}

Assistant Professor of Public Law, Al-Aqsa University, Gaza, Palestine wa.mezher@alaqsa.edu.ps

\author{
Received: 6/9/2021 Revised: 30/9/2021 Accepted: 12/1/2022 DOI: https://doi.org/10.31559/LCJS2021.2.3.4
}

Abstract: The study aimed to delve into the legal issue of judicial oversight over administrative discretionary authority, and that the presence of discretion in administrative work would achieve this legal presence of the state on the one hand, and on the other hand, would lead to the management and good performance of administrative public facilities. Moreover, for its significance, the descriptive analytical approach was used in conjunction with the comparative approach. As a result, the research was divided into three sections, the first of which addressed the nature of discretionary authority. The second is concerned with external judicial oversight of the limits of discretionary authority, as represented by the defects of lack of jurisdiction, form, procedures, and deviation in the use of authority and the third is concerned with internal judicial control over the limits of discretionary authority. We came to several conclusions and recommendations; one of the most important is that the administration's discretionary authority lies in the element of cause, place, and end. The restricted authority exists in jurisdiction and form. While the most important recommendations are represented in the administration's hope that should use the privileges granted to it under the law, particularly the discretionary authority, for the public interest.

Keywords: Judicial oversight; discretion; administrative judiciary; defect of lack of jurisdiction; defect of form; defect of reason; defect of shop.

\section{References:}

1. Ala'rj, Myswn Jrys 'Eysa (1999). 'yb Alsbb Fy Alqrar Aledary, Drash Mqarnh Wttbyqyh Fy Alardn. Rsalt Majstyr, Aljam'h Alardnyh, 'man, Alardn.

2. B'lwshh, Shryf (2010). D'wa Algha' Alqrar Aledary, Drash Thlylyh Mqarnh. Rsalt Majstyr Ghyr Mnshwrh, Jam't Alazhr, Flstyn.

3. Albna, Mhmd 'atf (1990). Alwsyt Fy Alqda' Aledary. Dar Alfkr Al'rby, Alqahrh.

4. Bsywny, 'bd Alghny (1996). Alqda' Aledary. Mnshah Dar Alm'arf, Aleskndryh.

5. Bsywny, 'bd Allh (D.T). Alnzryh Al'eamh Fy Alqanwn Aledary.

6. Btarsh, Slyman Slym (2003). 'yb Anhraf Alslth "Almstlh, Tby'h Al'yb Wtryqh Ethbath". Mjlt Drasat, Aljam'h Alardnyh, 30(2): 353 .

7. Hafz, Mhmwd (D.T). Alqda' Aledary. Altb'h Alsab'h, Alqahrh, Dar Alnhdh Al'rbyh.

8. Hjazy, Rda (2001). Alrqabh Alqda'yh 'la Rkn Alsbb Fy Ejra'at Aldbt Aledary, Drash Mqarnh Rsalh Dktwrah. Jam't Alqahrh.

9. Alhjr, 'amr Bn Mhmd Bn 'amr (D.T). Alrqabh Alqda'yh 'la 'yb Alsbb Fy D'wa Mraj't Alqrar Aledary. Mhkmt Alqda' Aledary.

10. Alhlw, Majd Raghb (1985). Alqda' Aledary, Dar Almtbw'at Aljam'yh, Alaskndryh, S377.

11. Hsn, 'bd Alftah (1971). Alt'wyd Fy Alqanwn Aledary Waledarh Al'amh. Alqahrh.

12. Hsn, 'bd Alftah (1982). Qda' Alelgha'. Mktbt Aljla' Aljdydh, Almnswrh.

13. Hsyn, Mhsn Aljwad (1953). Byn Slth Aledarh Altqdyryh Wakhtsasha Almqyd. Mjlt Mjls Aldwlh, Alsnh 04, Alqahrh.

14. Aljbwry, Mhmwd Khlf (D.T). Alqda' Aledary. Altb'h Alawla, Dar Althqafh Llnshr Waltwzy', 'man.

15. Aljrf, T'ymh (1973). Alqanwn Aledary- Drash Mqarnh-. Alqahrh.

16. Jmal Aldyn, Samy (D.T). Alqda' Aledary Walrqabh 'la A'mal Aledarh. Dar Aljam'h Aljdydh Llnshr Alqahrh. 
17. Khlyfh, 'bd Al'zyz 'bd Almn'm (2001). Alanhraf Balslth Ksbb Lelgha' Alqrar Aledary. Altb'h Alawla, Aleskndryh, Dar Alfkr Aljam'y.

18. Khlyfh, 'bd Al'zyz 'Ebd Almn'em (2007). Alqrarat Aledaryh Fy Alfqh Wqda' Mjls Aldwlh. Altb'h Alawla, Dar Alktb Almsryh, Msr.

19. Alrby'y, Syf Bn Bkhyt Bn Hmd (2018). B'nwan Ttwr Alqda' Aledary 'nd Rqabth 'la Rkn Alsbb, Wrqh 'ml Mqdmh Dmn F'alyat Alm'tmr Althamn Lr'sa' Almhakm Aledaryh Al'rbyh Almn'qd Balmrkz Al'rby Llbhwth Alqanwnyh Walqda'yh Bal'asmh Allbnanyh Byrwt Khlal Alftrh: Mn 24 Ela 26/9/2018m, Mhkmt Alqda' Aledary, Sltnt 'man.

20. Alsadq, Ahmd Frj (2019). 'b' thbat 'yb Alsbb Fy Alqrar Aledary. Mjlt Drasat Wabhath Almjlh Al'rbyh Fy Al'lwm Alensanyh Walajtma'yh, 11(2).

21. Sadq, 'ly (2008). D'wa Alelgha' y Alqda' Aledary Alflstyny. M'hd Albhwth Lldrasat Al'rbyh, Alqahrh.

22. Sary, Jwrjy Shfyq (D.T). Almbad' Al'amh Llqanwn Aledary " Alnshat Aledary. Jam't Almnswrh, Msr.

23. Shbyr, Mhmd Slyman Nayf (2015). Alqda' Aledary Fy Flstyn. Altb'h Alawla, Dar Alnhdh Al'rbyh, Alqahrh.

24. Alshryf, Hamd (D.T). Alt'n Fy Alqrarat Aledary Fy Almbany Amam Mhakm Mjls Aldwlh. D. T, Almktbh Al'almyh.

25. Shtnawy, 'ly Khatr (2004). Mwsw't Alqda' Aledary, Aljz' Alawl. Mktbt Dar Althqafh Llnshr Waltwzy', 'man, Altb'h Alawla, Alesdar Alawl, S751.

26. Shyha, Ebrahym 'bd Al'zyz (1994). Alqda' Aledary Allbnany Wmjls Shwra Aldwlh Allbnany. Aldar Aljam'yh, Byrwt.

27. Abw Smhdanh, 'bd Alnasr (2009). Alkhswmh Aledaryh Wmstqbl Alqda' Aledary Fy Flstyn, Drash Mqarnh. T1, Alqahrh, Dar Alnhdh Al'rbyh.

28. Alsnary, Mhmd 'bd (2000). Mbda Almshrw'yh Walrqabh 'la A'mal Aledarh Fy Dwlh Alamarat. Mtbw'at Jam't Alamarat Almthdh, Alamarat.

29. Tytawyn, Rmysh (2014). Dwr Alqda' Aledary Fy Hmayh Mbda Almshrw'yh. Rsalt Majstyr Ghyr Mnshwrh, Aljza'r.

30. Alznaty, Mstfa Asamh (2017). 'yb Alshkl Walajra'at Wathrh 'la Shh Alqrar Aledary Fy Alqanwn Alflstyny. Drash Thlylyh, Rsalt Majstyr, Brnamj Aldrasat Al'lya Almshtrk Byn Akadymyh Aledarh Walsyash Lldrasat Al'lya Wjam't Alaqsa Ghzh, Flstyn. 